\title{
NUMERICAL METHODOLOGY FOR THE CFD SIMULATION OF DIAPHRAGM VOLUMETRIC PUMPS
}

\author{
Menéndez Blanco, Alberto ; Fernández Oro, Jesus Manuel ${ }^{凶}$; Meana-Fernández, Andrés \\ Fluid Mechanics Area, Department of Energy, University of Oviedo \\ C/ Wifredo Ricart, s/n. Gijón, Asturias, 33204 Spain \\ jesusfo@uniovi.es (corresponding author)
}

\begin{abstract}
This paper presents the unsteady numerical methodology for the CFD simulation of AirOperated Diaphragm Pumps. The model reproduces the unsteady displacement of the diaphragm using dynamic mesh techniques and fully resolves the Fluid Structure Interaction (FSI) responsible for the motion of the check valves. The governing parameters have been modified with User Defined Functions (UDFs), using an implicit scheme for the grid motion that guarantees the stability and realizability of the twodimensional model adopted.

The analysis of the instantaneous delivered flow rate, as a function of the discharged outlet pressure, has provided interesting and useful information for the future design of new prototypes. The comparison between numerical results and the experimental performance curves has confirmed the accuracy of the model and the correct mesh selection in the small gaps and passages of the pump internal geometry.

The leakage flows, especially in the exhausting valve during the forward stroke, and the ball tapping responsible for instabilities and high-frequency noise during oscillations of the valves has been accurately simulated. At high-delivered pressures, it has been observed a characteristic ripple in the instantaneous flow rate during the deceleration of the diaphragm towards its top-dead-center, associated to a partial re-opening of the exhausting valve.

A closer look to the dynamics of the balls has revealed a strong coupling between inlet and outlet check valves. In addition, despite of the remarkable level of accuracy (less than $9 \%$ of deviation), the recirculating cells found in the flow fields inside the pump suggest the convenience of the development of a full-unsteady 3D model in the near future.
\end{abstract}

KEYWORDS: CFD Simulation, Air-Operated Double Diaphragm Pump, Dynamic Mesh, Numerical Methodology, Layering and remeshing techniques.

Revised Version 2.0, September, 17 $7^{\text {th }}, 2018$. 


\section{HIGHLIGHTS}

- CFD Modeling of an Air-Operated Double Diaphragm Pump for the first time.

- Dynamic meshes with implicit schemes fully resolve the Fluid Structure Interaction.

- Experimental tests have validated the numerical methodology used in a 2D model.

- Typical phenomena like ball tapping and flow leakage are accurately reproduced.

- Flow patterns within the pump advice for the need of a 3D model in future work.

\section{INTRODUCTION}

Diaphragm pumps are positive displacement pumps that use reciprocating deformable diaphragms to generate a pulsating discharge flow. The driving mechanism can be mechanical, using a typical crank gear mechanism to convert a rotational motion into an alternative motion of a piston attached to the diaphragm, or fluid-operated, where a secondary hydraulic fluid drives the motion from the opposing side of the diaphragm. In the case of using compressed air as the driving fluid, the pumps are usually doubleacting, incorporating two diaphragms and two sets of check valves, with the air flow being alternated between diaphragms via a shuttle valve. These pumps are usually known as Air-Operated Double Diaphragm (AODD) Pumps.

The working principle of these AODD pumps is simple. The compressed air is shifted from one chamber to the other by a pivoting pneumatic valve, while both diaphragms are moved simultaneously due to a central shaft. This reciprocating motion creates and collapses cavities forcing the liquid to get out of one chamber and go into a discharging manifold, while the other chamber is being filled with liquid coming from the inlet manifold at the same time. In addition, a set of check valves, operating due to the pressure differences in the chambers, are introduced to guarantee no recirculation.

AODD pumps are highly reliable, due to the absence of internal parts in friction, and they do not contain sealing or lubricating oils, so leakage and contamination of the pumping fluid is avoided. The inclusion of intermediate relief valves and additional ports to fullyload the hydraulic chambers help to enlarge the lifespan of the pump. They are used for a wide range of applications, going from petrochemical to sanitary or food and beverage industries, where highly abrasive or medium-to-high viscosity liquids must be transferred. Slurries and all sorts of aggressive fluids, even with high amount of solid contents, can be also easily handled by these pumps due to their good suction characteristics.

Manufacturers configure these pumps to the specific needs of a customer's application, including selection of materials and overall pump capacity, so the diaphragm has to be compatible with the pumped fluid and sized to match with the desired pump stroke and delivery flowrate. Most designs of AODD pumps are based on a peripheral layout of the flow passages, with the pneumatic motor being placed in the center of the pump, between both diaphragms, and ball valves acting as check valves $[1,2,3]$. The simplicity and the compatibility of the design to different materials and heavy fluids explains its predominant use in the industry (Figure 1, left). 
Recently, a new configuration with a central layout of the flow passages has been proposed by SAMOA Industrial S.A. [4,5]. The diaphragms are placed in the central position of the pump, in combination with the check valves, locating the pneumatic motor outside of the core and thus reducing the total length of the manifolds (Figure 1, right). This novel design presents lower internal pressure losses, higher compactness and superior lifespan of the diaphragms (due to the suppression of non-axial forces) with respect to classical designs.

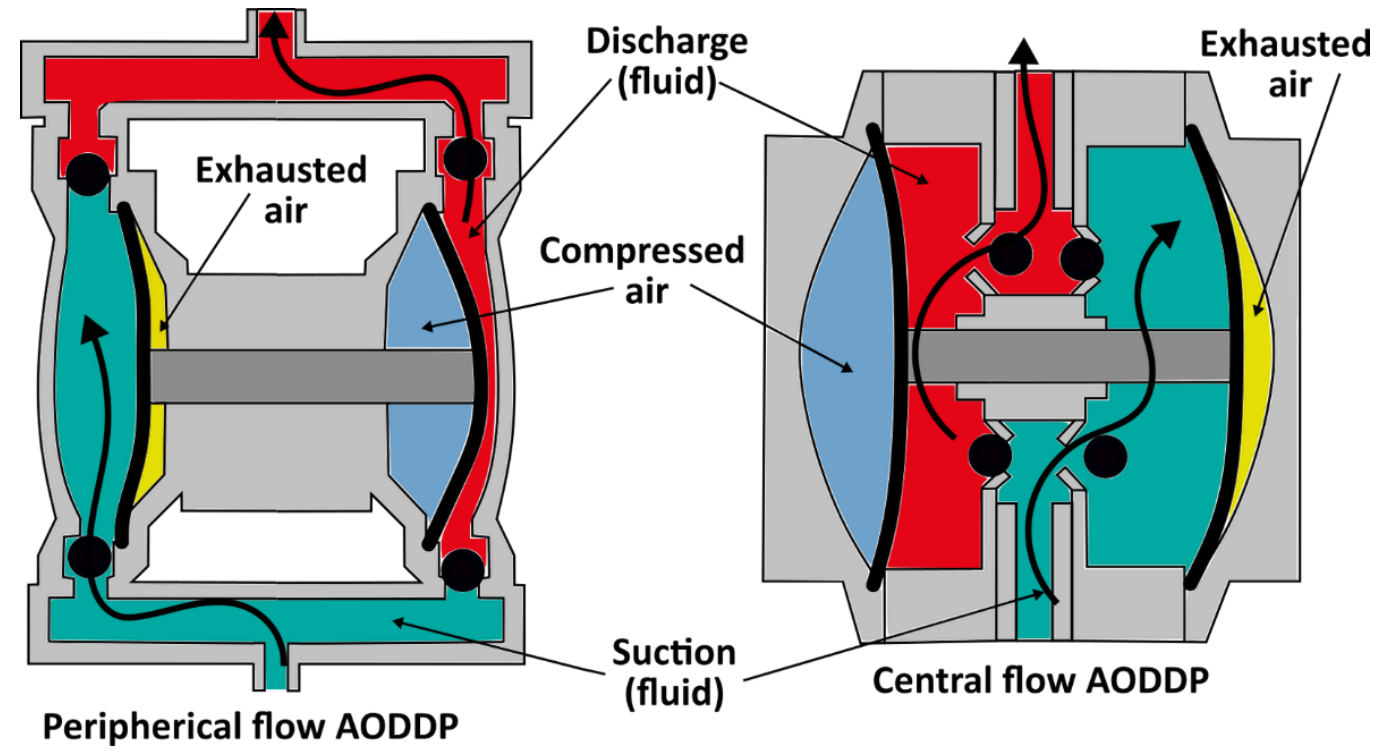

Figure 1. Peripheral layout (left) versus Central layout (right) of the flow passages in an AODD pump.

Due to the advances achieved in the design of centrifugal pumps during the last decades, and their low manufacturing costs, volumetric pumps have played a minor role in the pumping machinery field. Research activity has followed a similar trend, with a wide number of investigations on centrifugal pumps available in the literature, but only a very reduced significant research on volumetric pumps (even more marginal for diaphragm pumps). Typically, the development of AODD pumps has been based on experimental characterizations of their performance [6,7], mainly focused on the materials compatibility. Up to the authors' knowledge, no scientific references dealing with diaphragm pumps can be found in the open literature.

In order to propose a numerical model for the analysis of a diaphragm pump, other types of pumps with similar working principles can be referenced. In particular, both experimental and numerical investigations of axial piston pumps with check valves can be found and cited as preliminary studies for AODD pumps. Experimental studies have analyzed the characteristics of the valve motion of a reciprocating pump [8] and even the detection of cavitation phenomena using high-speed cameras [9], while 1D mathematical approaches have been proposed to model reciprocating pumps with selfacting valves numerically $[10,11]$, including pressure pulsations [12], or even alternative pumps with multiple cavities [13]. 
In addition, CFD simulations have recently emerged as a powerful tool to analyze in detail the spatial characteristics of the flow patterns within volumetric flow pumps. The performance of plunger pumps as a function of the crank angle [14], the evaluation of its inlet stroke performance [15] and even cavitation inception $[16,17]$ are some examples of the potentiality of computational modelling. The unsteady simulation of airoperated piston pumps [18] and the numerical analysis of axial piston pumps $[19,20]$ are also significant contributions for the study of reciprocating pumps via CFD. Complementarily, there are also relevant examples of CFD modelling for the study of the valve motion in check valves. The development of deformable meshes and the implementation of deforming grids [21] have allowed the optimization of check valve designs [22] and the analysis of fluid-structure interactions [23], even under incipient cavitation [24].

In the present investigation, a novel methodology for the computational analysis of volumetric diaphragm pumps is presented. In particular, an unsteady CFD modelling has been developed using deformable mesh techniques to simulate the flow patterns within an AODD pump. A set of user defined functions were developed to model accurately the dynamic movement of the pump diaphragm and the opening and closing of the check valves. This displacement is essential to model correctly the delivered flow rate as a function of the pressure differences in the chambers. In addition, implicit schemes for the grid motion were found to be necessary for stability and accuracy of the fluidstructure interaction (FSI) of the moving balls. Well-known phenomena like balls tapping, internal recirculations and volumetric losses have been successfully reproduced in the simulations. Moreover, typical delays for the opening and closing of the check valves have been well-reproduced by the model, and their behavior as a function of the air supply pressure or the pump working conditions has been also studied. The numerical model has been complemented with a set of laboratory tests for validation purposes. Unsteady pressure signals in the diaphragm cavities have been measured for different operating conditions of the pump and compared with the numerical data provided by the CFD model.

\section{STUDIED DIAPHRAGM PUMP (DP-200) AND OPERATING CYCLE}

SAMOA Industrial S.A. is a European manufacturer of equipment for fluid transfer, disposing, dosing, recovery and inventory control. Since 1985, SAMOA Group have been commercializing conventional AODD pumps that pump the fluid around the outside of the pump. To overcome the issues associated with these traditional models, a radical inside-out concept was developed in $\mathbf{2 0 0 0}$ to suppress peripheral manifolds. The pump was redesigned with a central flow path configuration and a new air distribution system.

Later, the central flow concept was reengineered in 2010 refining the critical elements and reducing the number of internal components. The so-called Directflo ${ }^{\circledR}$ pump (DP) is an extremely simple machine, very reliable with minimal maintenance requirements and typical delivered flow rates in the range between 30 and 100 liters per minute. In 2014, a new series of Directflo pumps has been designed to achieve delivered flow rates up to $200 \mathrm{l} / \mathrm{min}$. The DP-200 series has required a careful definition of the internal flow passages, the diaphragm size and the check valve geometries. The pump has been finally 
commercialized in February 2017. Figure 2 shows a photograph of the DP-200 pump, in both metallic and plastic versions (left image). On the right, an inner view reveals the different parts of the central flow concept.
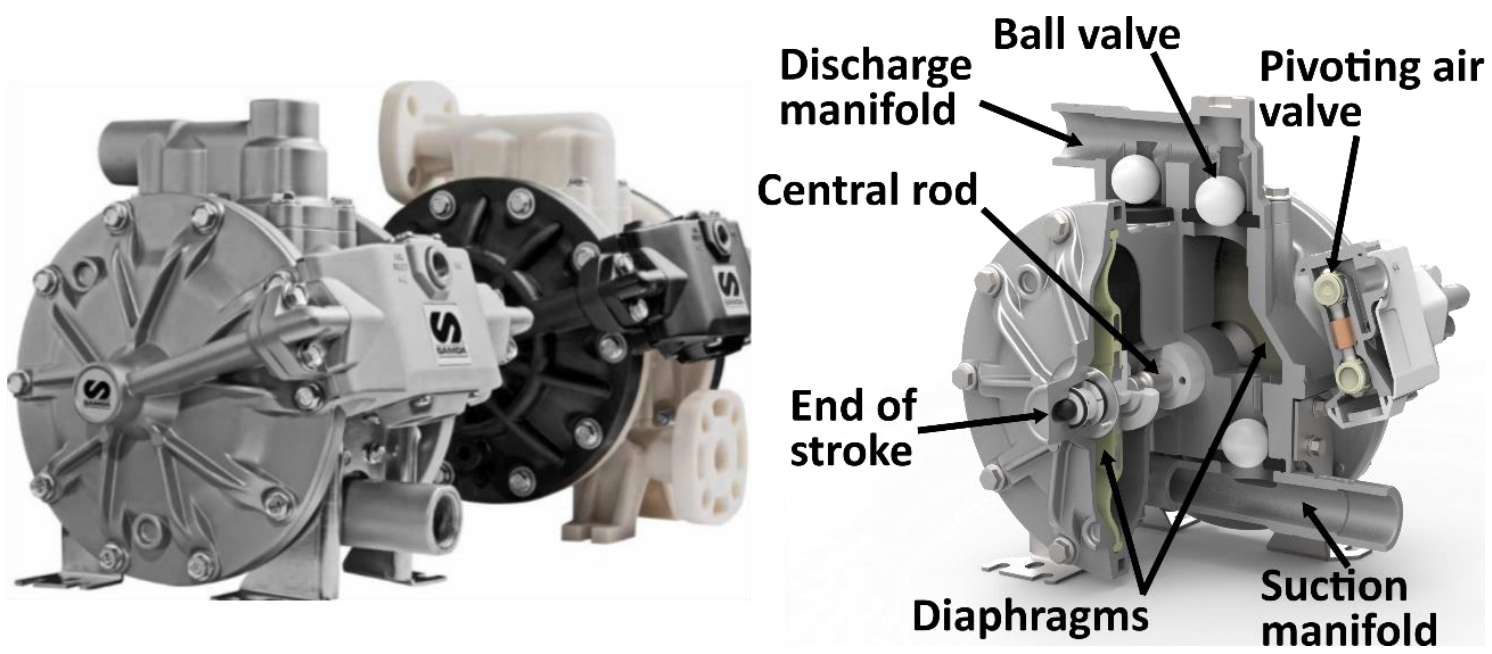

Figure 2. Metallic and plastic prototypes of DP-200 pump (left) and internal view of the basic elements (right).

These pumps feature two significant innovations: the flexible diaphragm suspension and the frictionless pivoting air valve. The diaphragm is a structured circular plate that incorporates a ribbed underside to provide higher strength and lifespan. The diaphragm is made of EPDM (Ethylene Propylene Diene Monomer) rubber as basic material, reinforced with a fabric and with a sheet of PTFE (Poly Tetra Fluoro Ethylene) thermallyadhered to the diaphragm side in contact with the media. The diaphragms are not rigidly fixed to the shaft, reducing fatigue and contributing to extend their service life since non-axial loads are not transmitted. On the other hand, a new frictionless and extremely fast air valve was developed to reduce the air consumption, reducing the fatigue wear and allowing shorter stroke lengths. Table 1 includes all the relevant geometrical data and summarizes the basic operating parameters of the pump.

Table 1. Geometrical data and operating parameters

\begin{tabular}{ll}
\hline Diaphragm external diameter, $\mathrm{D}_{\mathrm{e}}(\mathrm{mm})$ & 200 \\
Diaphragm internal diameter, $\mathrm{D}_{\mathrm{i}}(\mathrm{mm})$ & 100 \\
Diaphragm effective diameter, $\mathrm{D}_{\mathrm{d}}(\mathrm{mm})$ & 150 \\
Diaphragm stroke length, $\mathrm{L}_{d}(\mathrm{~mm})$ & 31.0 \\
Diaphragm effective area, $\mathrm{A}_{d}\left(\mathrm{~cm}^{2}\right)$ & 176.7 \\
Delivery per stroke, $\mathrm{V}_{\mathrm{d}}\left(\mathrm{cm}^{3}\right)$ & 548 \\
Internal manifolds diameter, $\mathrm{D}_{\mathrm{m}}(\mathrm{mm})$ & 26.5 \\
Ball diameter of check valves, $\mathrm{D}_{\mathrm{v}}(\mathrm{mm})$ & 31.75 \\
Ball maximum displacement, $\mathrm{L}_{\mathrm{v}}(\mathrm{mm})$ & 10 \\
Check valve effective area $(\mathrm{max}), \mathrm{A}_{\mathrm{v}}\left(\mathrm{cm}^{2}\right)$ & 4.98 \\
\hline Air-operation pressure, $\mathrm{P}_{\text {air }}(\mathrm{bar})$ & $0-8$ \\
Pressure ratio $(-)$ & $1: 1$ \\
Maximum free delivery $(8 \mathrm{bar}), \mathrm{Q}(\mathrm{l} / \mathrm{min})$ & 200 \\
Maximum driven velocity, $\mathrm{n}(\mathrm{Hz})$ & 3.0 \\
\hline
\end{tabular}



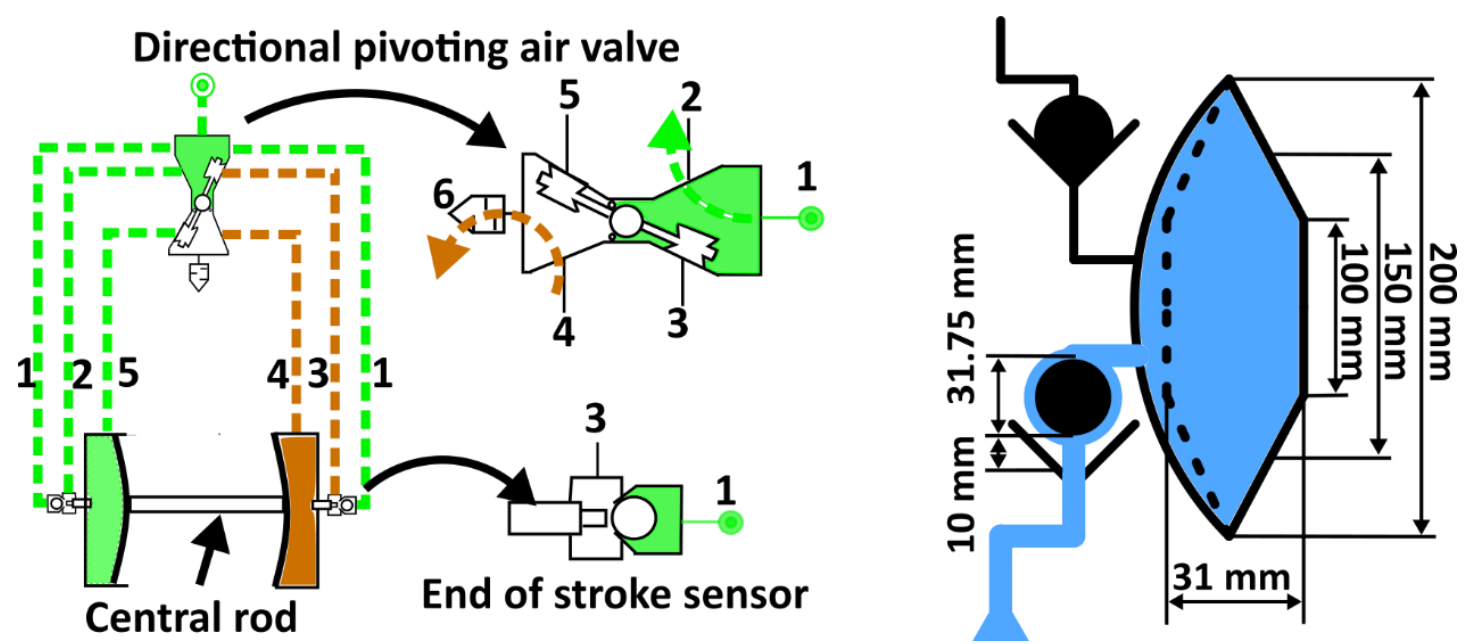

Figure 3. Sketch of the pneumatic operation (left) and basic dimensions of the diaphragm and check valves (right).

The operating cycle is a consequence of the alternative displacement imposed in the diaphragms by the pneumatic valve. When one of the diaphragms moves out, a volume in one chamber is created causing the pressure to decrease and suction fluid into the pump. At the same time, the other chamber is collapsed and the fluid in contact with the second diaphragm is discharged out of the pump. When diaphragms reach their bottom and top dead centers (BDC, TDC) respectively, a pneumatic end stroke sensor is triggered and the directional valve is inverted. Due to the pressure differences created, the ball valves are also activated at the beginning of every back-and-forth stroke, with some delay due to inertial forces. Figure 3 shows a sketch of the operating cycle, including the basic dimensions of the working elements.

\section{PERFORMANCE CURVES AND EXPERIMENTAL SENSORS}

The experimental performance curves of the DP-200 AODD pump have been obtained by the manufacturer in the prototypes laboratory of the R\&D department of SAMOA Industrial S.A. using water as the working fluid. The test facility is composed of a closedloop hydraulic circuit connecting two atmospheric tanks with free-surface level sensors, following the standards ANSI/HI 10.6-2004 by the Hydraulic Institute [7] (see Figure 4, left). The delivered flow rate of the pump, installed between the tanks, is measured volumetrically comparing the time required to displace a given amount of fluid. The amount of water is calibrated on-line using an electronic balance. The pressure rise given by the pump is obtained through the measurement of the inlet and outlet static pressures of the pump with electronic manometers (Figure 4, right). 

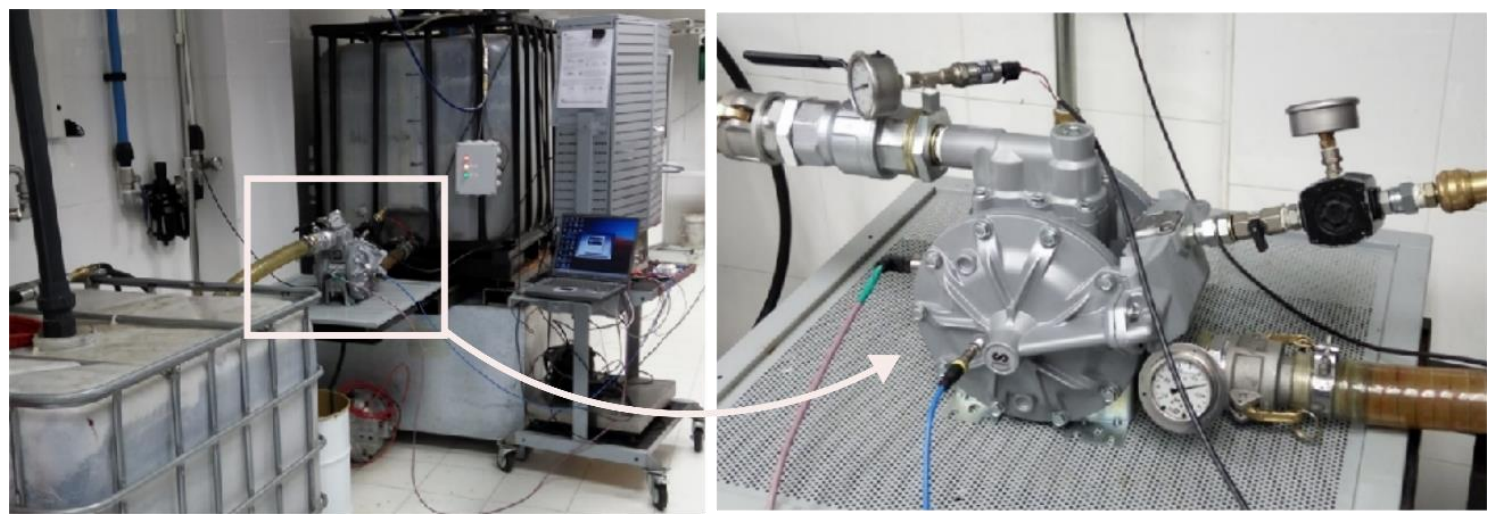

Figure 4. Test laboratory in the R\&D Department at SAMOA Industrial S.A. (left) and detail of the pump instrumented with the measuring sensors (right).

The pump is also instrumented with an inductive sensor, to obtain the instantaneous position of the diaphragm, and a pressure transducer to measure the static pressure in the hydraulic chamber. In addition, the working point for the pump can be modified using a throttle valve in the primary line of the circuit and the air-supplied pressure can be also regulated between 0 and 8 bar for different air consumptions, which is measured with a thermal flowmeter. Figure 5 shows a sketch of the hydraulic facility and Table 2 gives the accuracy and precision of the measuring devices.

Table 2. Accuracy and precision of the measuring equipment.

\begin{tabular}{llcc}
\hline Measuring device & Manufacturer and model & Range & Uncertainty \\
Inductive sensor & PEPPERL-FUCHS NBN-8GM30-E2V1 & $0-3 \mathrm{~mm}$ & 5\% (hysteresis) \\
Pressure transducer & TE Connectivity MEAS U5244 & -1 to 13 bar & $\pm 1 \%$ \\
Pressure transducer & ESI Genspec GS4002 & -1 to 24 bar & $\pm 1 \%$ \\
Electronic manometer & Parker Service Junior SCJN-016-01 & -1 to $16 \mathrm{bar}$ & $\pm 0.5 \%$ \\
Thermal flowmeter & Testo 6442 & 12 to $3750 \mathrm{lpm}$ & $\pm 0.3 \%$ \\
\hline
\end{tabular}

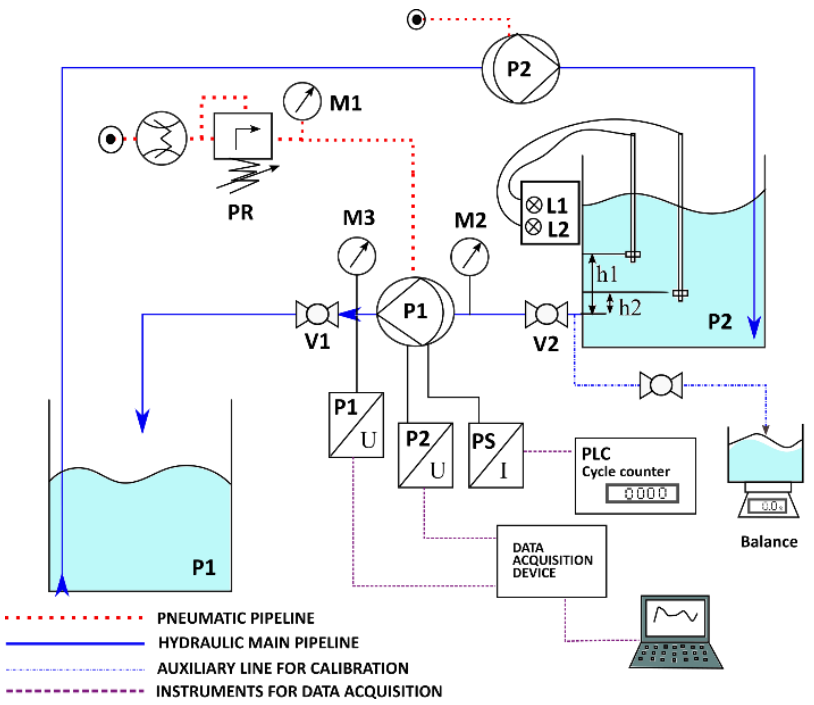

\begin{tabular}{|c|c|c|c|c|c|}
\hline \multicolumn{2}{|r|}{$\begin{array}{l}\text { Pneumatic } \\
\text { circuit }\end{array}$} & \multicolumn{2}{|c|}{ Hydraulic circuit } & \multicolumn{2}{|r|}{ Sensor } \\
\hline ID & Description & ID & Description & ID & Description \\
\hline$F$ & Flowmeter & T1 & $\begin{array}{l}\text { Lower tank } \\
1000 \text { capacity }\end{array}$ & PS & Proximity sensor \\
\hline M1 & Manometer & T2 & $\begin{array}{l}\text { Upper tank } \\
1000 \text { l capacity }\end{array}$ & PT1 & $\begin{array}{l}\text { Pressure } \\
\text { transducer } \\
\text { (pump discharge) }\end{array}$ \\
\hline \multirow[t]{6}{*}{ PR } & $\begin{array}{l}\text { Air pressure } \\
\text { regulator }\end{array}$ & P1 & $\begin{array}{l}\text { Diaphragm } \\
\text { pump under } \\
\text { study (P200) }\end{array}$ & PT2 & $\begin{array}{l}\text { Pressure } \\
\text { transducer } \\
\text { (diaphragm } \\
\text { chamber) }\end{array}$ \\
\hline & & P2 & $\begin{array}{l}\text { Auxiliary pump } \\
\text { CF40 }\end{array}$ & L1 & $\begin{array}{l}\text { Level sensor } \\
\text { (tank 1) }\end{array}$ \\
\hline & & M2 & $\begin{array}{l}\text { Inlet } \\
\text { manometer }\end{array}$ & L2 & $\begin{array}{l}\text { Level sensor } \\
\text { (tank 2) }\end{array}$ \\
\hline & & M3 & $\begin{array}{l}\text { Outlet } \\
\text { manometer }\end{array}$ & & \\
\hline & & V1 & $\begin{array}{l}\text { Flow rate } \\
\text { regulating valve }\end{array}$ & & \\
\hline & & V2 & $\begin{array}{l}\text { Upper tank } \\
\text { valve }\end{array}$ & & \\
\hline
\end{tabular}

Figure 5. Sketch of the hydraulic circuit for the experimental database (left) and list of the basic elements (right). 
To characterize the performance curves of the pump, three different air-supplied pressures (2, 4 and 6 bar) have been tested for different discharge pressures in the throttle valve. Hence, the experimental database is composed of 9 different working conditions (see table 3).

Table 3. Experimental database.

\begin{tabular}{cccccccc}
\hline $\begin{array}{c}\text { Test } \\
\text { No. }\end{array}$ & $\begin{array}{c}\text { Air-supply } \\
\text { pressure } \\
\text { (bar) }\end{array}$ & $\begin{array}{c}\text { Discharge } \\
\text { pressure } \\
\text { (bar) }\end{array}$ & $\begin{array}{c}\text { Volume } \\
\text { (l) }\end{array}$ & $\begin{array}{c}\text { Time } \\
\text { (s) }\end{array}$ & $\begin{array}{c}\text { Flow rate } \\
\text { (I/min) }\end{array}$ & $\begin{array}{c}\text { Driving } \\
\text { frequency } \\
\text { (Hz) }\end{array}$ & $\begin{array}{c}\text { Normalized } \\
\text { Efficiency } \\
(-)\end{array}$ \\
\hline$\# 1$ & 2 & 0 & 200 & 107 & 112.2 & 1.85 & 0.00 \\
$\# 2$ & 2 & 1 & 200 & 206 & 58.2 & 1.0 & 0.36 \\
$\# 3$ & 4 & 0 & 200 & 83.9 & 144.6 & 2.45 & 0.00 \\
$\# 4$ & 4 & 1.5 & 200 & 143 & 83.9 & 1.4 & 0.31 \\
$\# 5$ & 4 & 3 & 200 & 504 & 23.8 & 0.45 & 0.47 \\
$\# 6$ & 6 & 0 & 200 & 76 & 157.8 & 2.7 & 0.00 \\
$\# 7$ & 6 & 1.5 & 200 & 104 & 115.4 & 1.8 & 0.24 \\
$\# 8$ & 6 & 3.0 & 200 & 159 & 75.5 & 1.25 & 0.40 \\
$\# 9$ & 6 & 4.5 & 200 & 282 & 42.6 & 0.75 & 0.50 \\
\hline
\end{tabular}

The performance curves (pressure rise and normalized efficiency as a function of the flow rate for different air-supplied pressures) are shown in Figure 6. The efficiency has been obtained as the ratio between the fluid power and the driving power of the pneumatic supply. According to the manufacturer, it has been defined that nominal points correspond to working situations where the discharge gauge pressure is approximately 1 bar (typical situations for transport of low-viscosity liquids). Additionally, using the theory of transmission of uncertainty, we have estimated the following precision for the figures of merit of the volumetric pump: 0.12 bar in the measurements of the pressure rise given by the pump and maximum uncertainty of $0.7 \%$ in the measurement of the flow rate.

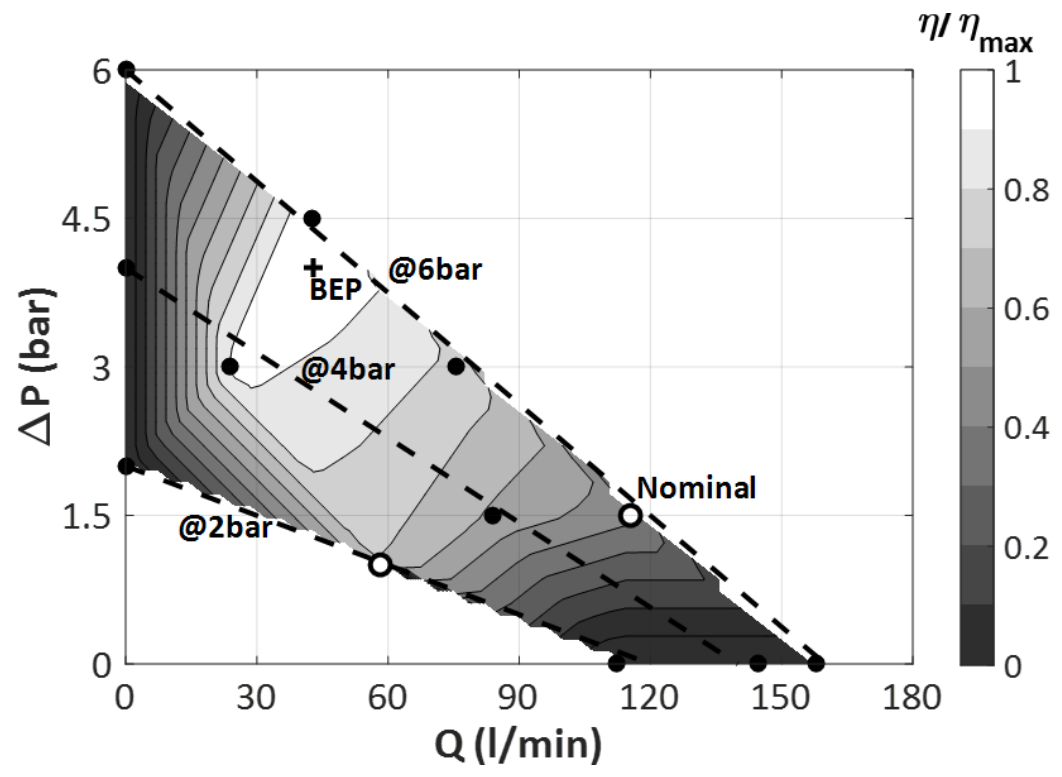

Figure 6. Performance curves of the AODD pump: Pressure rise and normalized efficiency as a function of the flow rate. 


\section{NUMERICAL METHODOLOGY}

The commercial package ANSYS-FLUENT ${ }^{\circledR}$ v16 [25] has been used to resolve the set of Reynolds-Averaged Navier-Stokes (RANS) equations with a finite volume approach. A dynamic based technique, using remeshing and layering functionalities, have been employed for the simulation of the alternative deformation of the diaphragm and the induced motion of the ball valves.

\subsection{Numerical scheme}

The Finite Volume Method (FVM) is employed to resolve the fluid governing equations for incompressible flow using the RANS approach:

- Continuity equation:

$$
\frac{\partial \bar{u}_{i}}{\partial x_{i}}=0
$$

- Momentum equation:

$$
\rho \frac{\partial \bar{u}_{i}}{\partial t}+\rho \frac{\partial\left(\bar{u}_{i} \bar{u}_{j}\right)}{\partial x_{j}}=-\frac{\partial \bar{p}}{\partial x_{i}}+\mu \nabla^{2} \bar{u}_{i}+\frac{\partial \tau_{i j}}{\partial x_{j}}
$$

In this case, a second-order upwind spatial scheme has been employed for the convection terms, with a Green-Gauss cell based method for the computation of spatial gradients in diffusion terms of the momentum equation. A segregated solver with the SIMPLE pressure-velocity coupling was firstly employed for preliminary simulations in a steady fashion. Later, it was switched to a PISO algorithm for the dynamic simulations with the deformable mesh.

In addition, due to the turbulent regime of the flow inside the pump, a $k-\varepsilon$ RNG turbulence model with standard wall functions was selected due to its robustness and versatility for a wide range of fluid machinery applications [26]. Moreover, this option includes the effect of swirl in turbulence and also accounts for low Reynolds number effects. Thus, the Reynolds Stress Tensor in the momentum equation is modelled using an Eddy Viscosity Model, according to:

$$
\tau_{i j}=-\rho \overline{u_{\imath}^{\prime} u_{j}^{\prime}}=\mu_{t} \underbrace{\left(\frac{\partial \bar{u}_{i}}{\partial x_{j}}+\frac{\partial \bar{u}_{j}}{\partial x_{i}}\right)}_{S_{i j}}-\frac{2}{3} \rho k \delta_{i j}
$$

where $k=\frac{1}{2} \rho \overline{u_{k}^{\prime} u_{k}^{\prime}}$ is the turbulent kinetic energy and $\mu_{t}=\rho C_{\mu} \frac{k^{2}}{\varepsilon}$ is the turbulent viscosity, with $C_{\mu}=0.0845$. Additional transport equations are required for the turbulent kinetic energy and the turbulent dissipation rate, $\varepsilon=2 v \overline{s_{l j}^{\prime} s_{l j}^{\prime}}$, being $s_{i j}^{\prime}=$ $\frac{1}{2}\left(\frac{\partial u_{i}^{\prime}}{\partial x_{j}}+\frac{\partial u_{j}^{\prime}}{\partial x_{i}}\right)$. In the case of the RNG model, these closure equations are for this case (neglecting buoyancy): 


$$
\begin{gathered}
\rho \frac{\partial k}{\partial t}+\rho \frac{\partial\left(k \bar{u}_{i}\right)}{\partial x_{i}}=\frac{\partial}{\partial x_{j}}\left[\alpha_{k} \mu_{t} \frac{\partial k}{\partial x_{j}}\right]+2 \mu_{t} S_{i j} S_{i j}-\rho \varepsilon \\
\rho \frac{\partial \varepsilon}{\partial t}+\rho \frac{\partial\left(\varepsilon \bar{u}_{i}\right)}{\partial x_{i}}=\frac{\partial}{\partial x_{j}}\left[\alpha_{\varepsilon} \mu_{t} \frac{\partial \varepsilon}{\partial x_{j}}\right]+C_{\varepsilon 1} \frac{\varepsilon}{k}\left(2 \mu_{t} S_{i j} S_{i j}\right)-\rho C_{\varepsilon 2} \frac{\varepsilon^{2}}{k}
\end{gathered}
$$

with typical coefficients $C_{\varepsilon 1}=1.42, C_{\varepsilon 2}=1.68$ and $\alpha_{k}=\alpha_{\varepsilon} \sim 1.383$.

A convergence criterion of $10^{-6}$ was fixed in the continuity equation for all the cases simulated. Typical convergence thresholds of $10^{-8}$ for the two velocity components and $10^{-7}$ for turbulent variables were also guaranteed.

In summary, for this numerical model, the following assumptions have been adopted:

- Two-dimensional simulation of the transversal, central section of the AODD pump for both static and dynamic (unsteady) conditions using deformable mesh.

- Incompressible, viscous flow of a single-phase Newtonian fluid (water). Thermal and buoyancy effects have been neglected.

- Turbulent flow regime with a characteristic Reynolds number of 60000 (based on the diameter of the balls and the flow velocity in the vicinity of the valves), resolved with a two-equation turbulent modelling.

- Implicit resolution of the flow fields using a pressure-based solver with also an implicit scheme of the grid motion when using dynamic mesh (see section 4.6 later). Implementation of parametric UDFs to simulate the alternative displacement of the diaphragm and the FSI of the check balls.

\subsection{Baseline mesh and boundary conditions}

Firstly, a 2D baseline mesh was resolved in a steady model as a first approach to the problem in order to define an accurate cell density and a correct identification of the critical parameters. A transversal section of the AODD pump, comprising one of the two diaphragms only, is considered as the representative domain for the simulations. Also, the inlet and outlet interior manifolds of the pump have been rotated 90 deg in order to be aligned with the diaphragm axis.

For economy, a hybrid 2D structured mesh was implemented in the whole domain using the grid builder ANSYS-ICEM ${ }^{\circledR}$ v16.2 [27]. The complete geometry was split in different rectangular blocks that are later reshaped to match with the real contours of the pump (see Figure 7, left). Afterwards, every block is meshed using structured cells. Local refinements have been introduced towards the end-walls and in the small gaps between the different elements of the pump. Typical $y+$ values in the range between 3 and 6 have been found in the valve walls. With this strategy, it was possible to obtain minimum skewness (index below 0.45) and high orthogonal qualities (index above 0.55). Since the diaphragm region will require a remeshing utility for the dynamic approach, a mesh with triangular cells was already introduced in that zone (see Figure 7 , right). 


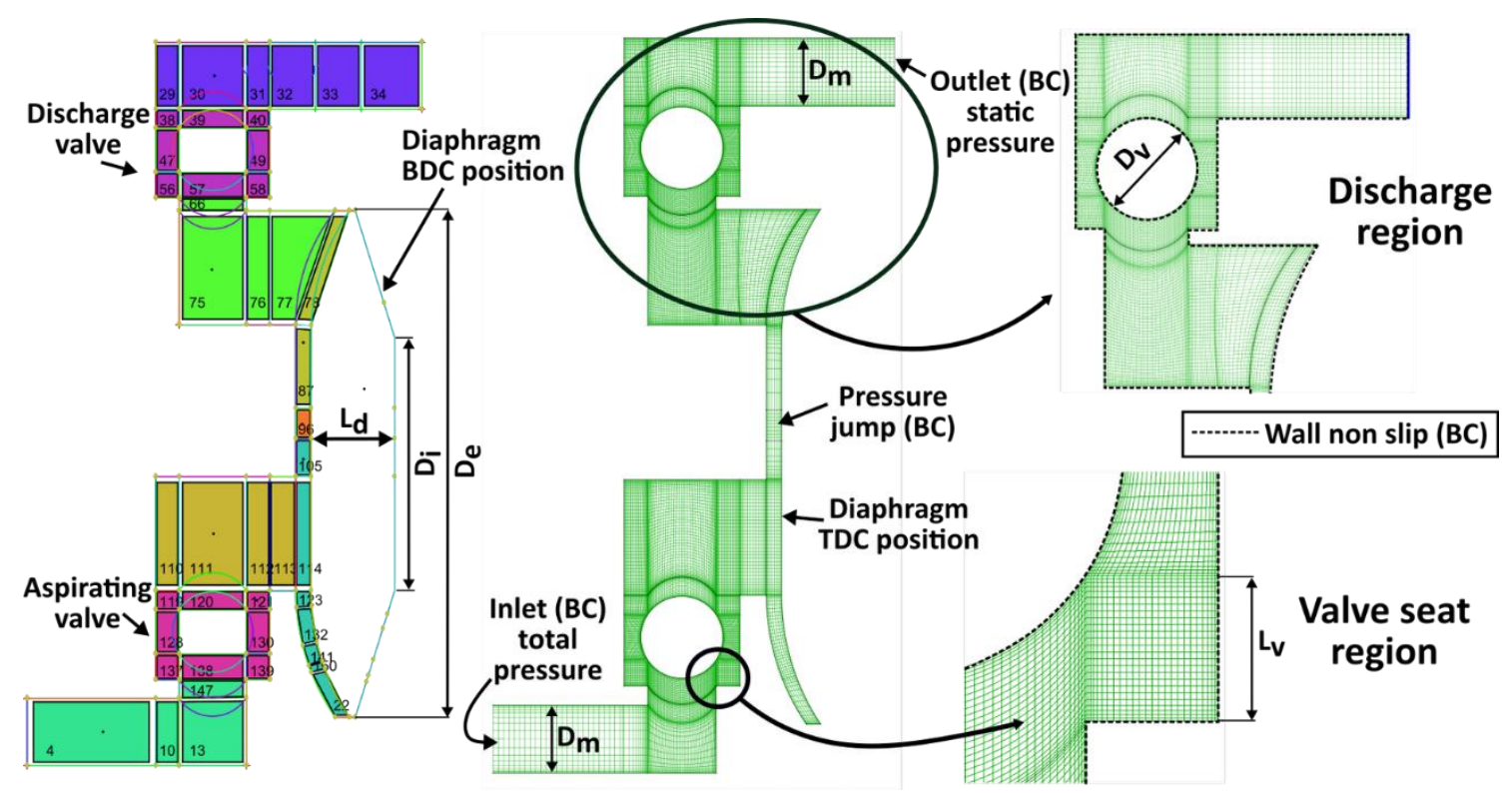

Figure 7. Multiblock meshing strategy in ICEM (left) and final structured mesh with local refinements (right).

The different boundary conditions introduced in the model are also represented in Figure 7 (identified with additional annotations). For the ending sections of the domain, a total pressure equal to zero at the inlet $\left(p_{0}^{i n}=0\right)$ and a pressure drop proportional to the kinetic energy at the outlet $\left(\Delta p=K_{v} v_{o u t}^{2}\right)$, representing different throttle valve conditions, were defined. Precisely, this outlet boundary condition allows to change the flow rate conditions, imposing different values of the constant $K_{v}$ which mimics the closure of the valve. In particular, the values of $K_{v}$ employed to obtain different averaged static pressure at the outlet are summarized later in Table 5. All the solid boundaries have been defined as non-slip end-walls (in case of moving zones, the walls are also defined stationary in the relative frame of reference, $\vec{v}=0$ ). Finally, to simulate the pressure rise given by the volumetric principle using a steady model, an actuator disc approach was implemented in the middle section of the diaphragm at its TDC and the ball valves were set to their opening position to allow a continuous flow delivery.

\subsection{Static model}

In order to compare the results of this 2D static model with the real 3D experimental curves, it is necessary to introduce some scaling factors. Calculating the ratio of the volumetric flow rates generated by the diaphragm in both $2 \mathrm{D}$ and $3 \mathrm{D}$ situations (in 2D, the flow rate is per unit length; whereas in $3 D$ is considering the real area of the diaphragm) and imposing that value for the delivered flow rate at the discharge sections, a scaling factor for the velocities between the 2D and 3D cases is obtained. On the other hand, assuming that pressure losses inside the passages of the pump are quadratic with respect to the bulk velocities, a scaling factor for the pressure values can be also derived, yielding to:

$$
\frac{v_{3 D}}{v_{2 D}}=\left(\frac{D_{d}}{D_{m}}\right) \quad ; \quad \frac{\Delta p_{3 D}}{\Delta p_{2 D}}=\left(\frac{D_{d}}{D_{m}}\right)^{2}
$$


Where $D_{d}$ stands for the effective diameter of the diaphragm and $D_{m}$ is the diameter of the discharge manifold.

Under free delivery conditions, the experimental flow rate is firstly used to calibrate the model: A tentative pressure rise is iterated until the desired flow rate is obtained. With that solution, the pressure loss coefficient of the hydraulic model can be determined. This coefficient is thus imposed for the hydraulic losses in the rest working points simulated. Following, the pressure rise is intended in the other cases (to reproduce the experimental values) and the delivered flow rate by the pump in the model is finally considered as an estimation of the solution. Table 4 shows the comparison of the experimental values (when working at non-zero discharge pressure) with the numerical estimations. Note that the assumption of constant loss coefficient is validated due to the reduced deviation (a maximum 15\%) of the numerical solutions. In addition, these results confirm that the spatial discretization adopted for the model can be accepted (in these applications, the precise computation of the fluid turbulent boundary layer and the associated pressure losses are marginal with respect to the pressure rises generated volumetrically).

Table 4. Comparison of experimental and numerical results.

\begin{tabular}{cccccc}
\hline $\begin{array}{c}\text { Test } \\
\text { No. }\end{array}$ & $\begin{array}{c}\text { Air-supply } \\
\text { pressure (bar) }\end{array}$ & $\begin{array}{c}\text { Discharge } \\
\text { pressure (bar) }\end{array}$ & $\begin{array}{c}\text { Experimental } \\
\text { flow rate } \\
\text { (1/min) }\end{array}$ & $\begin{array}{c}\text { Numerical } \\
\text { flow rate } \\
\text { (I/min) }\end{array}$ & $\begin{array}{c}\text { Relative error } \\
\text { (\%) }\end{array}$ \\
\hline 4 & 4 & 1.5 & 83.9 & 80.9 & 3.57 \\
5 & 4 & 3 & 23.8 & 20.2 & 15.1 \\
7 & 6 & 1.5 & 115.4 & 113.1 & 1.99 \\
8 & 6 & 3.0 & 75.5 & 71.6 & 5.16 \\
9 & 6 & 4.5 & 42.6 & 38.2 & 10.3 \\
\hline
\end{tabular}

Also, and because of the relatively low Reynolds number in the pump, the results for the $k-\varepsilon$ RNG model have been compared with other two-equation turbulence models for low Re: The Realizable $k-\varepsilon$ and the $k-\omega S S T$. The results obtained for the flow patterns at the TDC are shown in Figure 8. Both $k-\varepsilon$ models present a very similar behavior, with the RNG being more susceptible for internal recirculations. The flow pattern in the gap of the discharge valve is practically identical, although there are also significant differences in the outgoing flow close to the domain outlet. In the case of the $k$ - $\omega S S T$ model, a large recirculation cell (established downstream of the ball) induces a large blockage and a broader jet that leads to an earlier detached flow on the sphere, resembling the characteristics of a laminar regime. Though not shown here, the analysis of the ball motions with the dynamic mesh also reveals that the instantaneous response of the valves is severely mitigated with the SST model, thus underpredicting inertial effects on the flow. Hence, for this application, it is concluded that the $k-\omega$ option introduces excessive damping to instabilities and ball oscillations and it should not be recommended for the modelling of turbulence. 


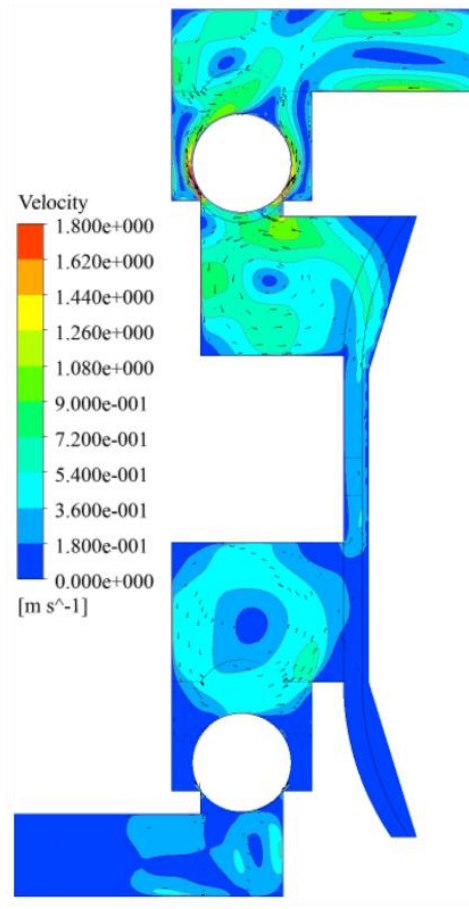

k-epsilon (RNG)

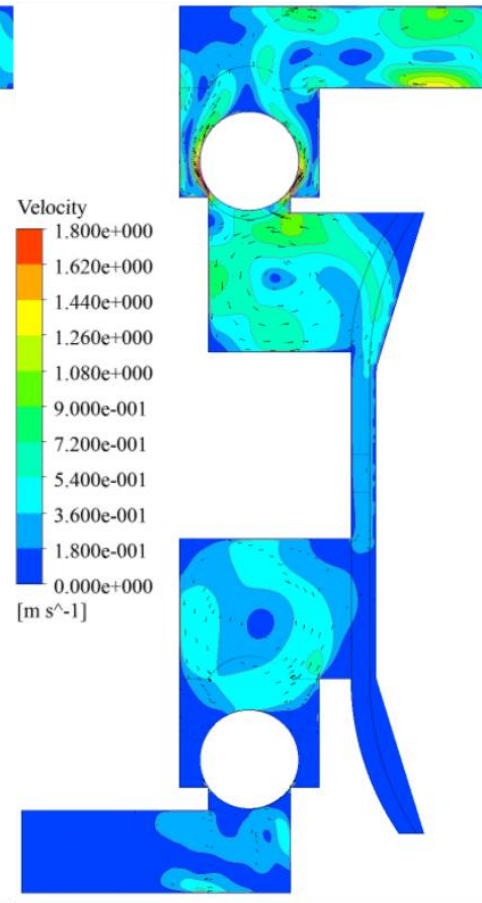

k-epsilon (Realizable)

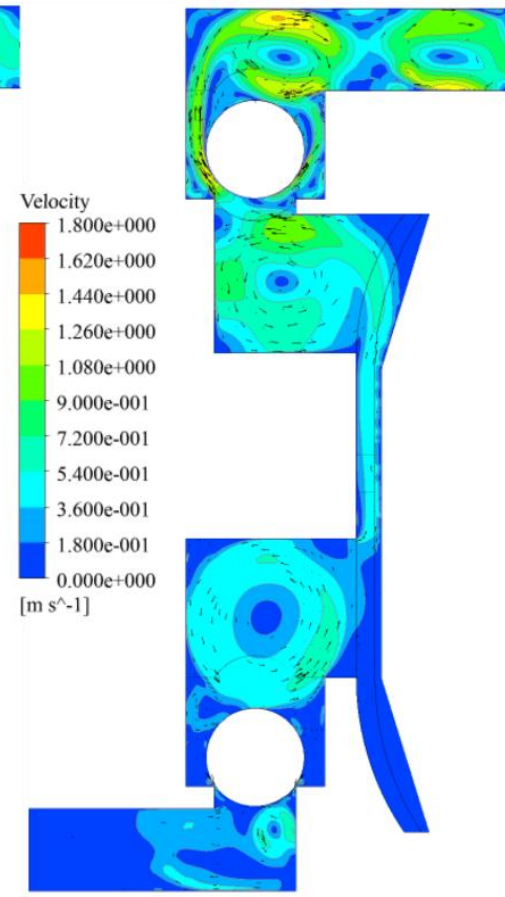

k-omega (SST)

Figure 8. Comparison of flow patterns (velocity contours) for different turbulence models: $k-\varepsilon R N G$; $k-\varepsilon$ Realizable; $k-\omega S S T$

\subsection{Dynamic meshes: remeshing \& layering techniques.}

After the validation of the baseline mesh, the next step is the introduction of deformable regions in the numerical model. Dynamic techniques allow the displacement of the domain boundaries in the CFD simulations, adjusting the associated meshes accordingly. The solid boundaries can be modified in time due to a prescribed motion or due to the interaction with the fluid (fluid-structure interaction). To introduce this technique, the grid velocity of the boundaries has to be introduced in the conservation equations [28]. Hence, it is possible to evaluate correctly both inlet and outlet flows on that moving zones and also take into account the variation of the cells size in the temporal term of the equations.

Basically, three fundamental methods for mesh reconstruction can be found in the literature: smoothing, layering and remeshing techniques. However, smoothing is only viable in case of small deformations, so it has been discarded for the present application. For the check valves, taking advantage of the linear up-and-down motion of the balls, a layering method was employed due to its higher efficiency and economy. It was necessary to encapsulate the balls in a body-fitted cylinder (Figure 9, left) with a structured mesh in order to allow an efficient generation and collapse of cell rows. Moreover, the cylinder sidewall was defined as a sliding interface to allow the flow between fluid zones. For the diaphragm, due to the its flexible motion (from concave to convex in every stroke), a remeshing technique was used so the mesh had to be rebuilt after updating the diaphragm in every time step of the simulation (Figure 9, right). 
Precisely, the velocity of the mesh nodes co-located in the diaphragm is imposed with a compiled User Defined Function (UDF) that associates a cosine law for the movement of the diaphragm. Note that the amplitude of every node is a function of its radial position with respect to the center of the diaphragm, thus allowing the periodic deformation of the diaphragm, according to $x_{P}(t)=\frac{A_{d}}{2} \cos (2 \pi f t)$. Here, $x_{P}$ corresponds to the position of the node overtime, $t ; A_{d}$ is the amplitude of the node (equal to the diaphragm stroke, $L d$, in the non-deformable inner disc of the diaphragm; and with a decreasing linear variation in the deformable outer ring) and $f$ is the reciprocating frequency.

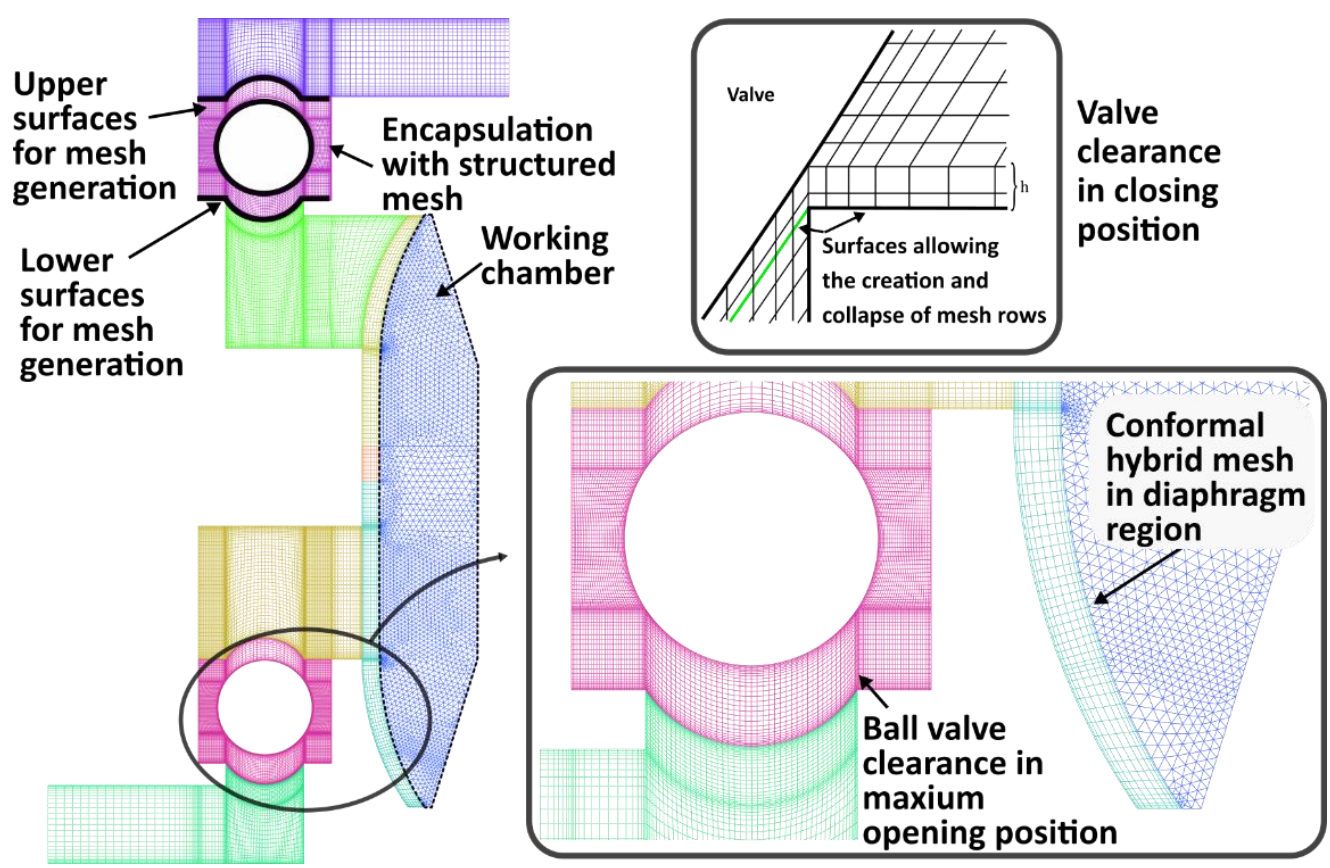

Figure 9. Details of the remeshing and layering techniques.

\subsection{Used Defined Functions (UDFs)}

The behavior of the deformable regions is controlled with User Defined Functions (UDFs) which include the governing laws for the displacements of the diaphragm and the check valves.

On the one hand, the diaphragm motion is prescribed with two remeshing functions for the diaphragm in the first UDF. A Define-Grid-Motion macro is executed at the beginning of every time step to identify those nodes of the domain located on the diaphragm and to relocate them to their new positions. Following, a Define-Adjust macro is called at the first iteration to calculate the grid velocity of the nodes, which is simply computed as the relative movement divided by the time step (Figure 10). The UDF also includes control parameters for the stability and accuracy of the dynamic mesh like the spring constant, set to 0.3 , or the threshold values for setting off the remeshing: cells sizes between 0.1 and $1.5 \mathrm{~mm}$ (minimum and maximum cell sizes permitted) and maximum skewness of 0.7 . 
On the other hand, the second UDF for the check valves includes only one function for layering. The motion of the balls as rigid bodies is controlled with a Define-CG-Motion macro that is executed at the beginning of every time step. In this kind of macros, the current velocity of the ball must be given as an input, so it has to be calculated in the UDF code as a function of the velocity at the end of the previous time step and the corresponding fluid forces acting on the ball. According to an explicit, first-order numerical integration, this can be expressed as:

$$
\int_{t-\Delta t}^{t} d v=\int_{t-\Delta t}^{t}\left(\frac{F}{m_{b}}\right) d t \Rightarrow v_{t}=v_{t-\Delta t}+\left(\frac{F}{m_{b}}\right) \Delta t
$$

Where $F$ is the force exerted by the fluid (including both viscous and pressure terms) and $m_{b}$ is the mass of the ball. Following, the position of the ball is also calculated from the velocity value according to $y_{t}=y_{t-\Delta t}+v_{t} \Delta t$, although it is mandatory to check if the ball is still placed between upper $\left(y_{t}<10 \mathrm{~mm}\right)$ and bottom $\left(y_{t}>0 \mathrm{~mm}\right)$ tops. Otherwise, the velocity is set to zero to avoid further non-allowed movements.
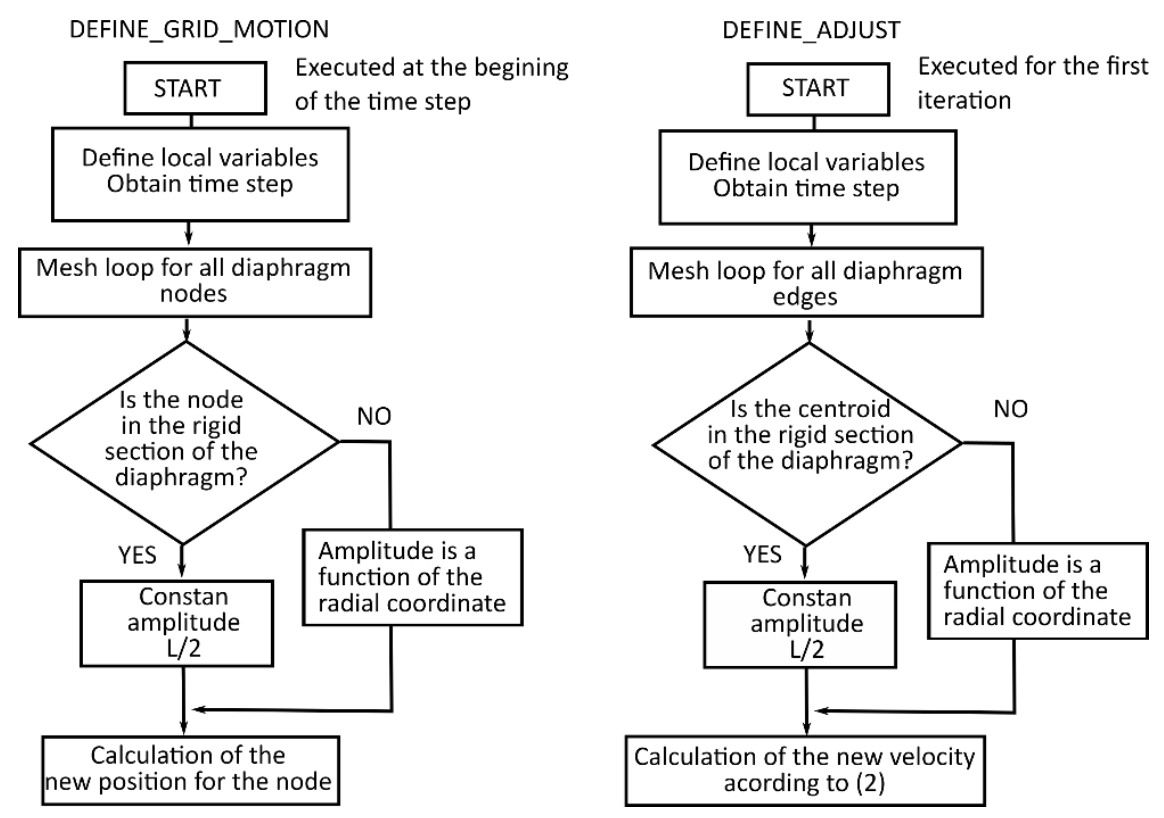

Figure 10. Sequence of the UDFs for the remeshing routines with the explicit scheme.

Note that every ball has to be tracked with its own particular macro. In this case, the control parameters of the layering are the collapse factor, which is set to 0.2 (cells are suppressed when its size is only a $20 \%$ of the original one), and the splitting factor, which is set to 0.4 (a cell is divided in two when its size is a $140 \%$ larger than the original value). 
Complementarily, a third UDF based on the Define-Execute-At-End macro is implemented in the code to perform post-processing routines like collecting relevant data and/or exporting main variables into output files. Figure 11 shows the necessary sequence followed to employ the layering macro in an explicit fashion. More details with complete coding of the UDFs can be found in [29].

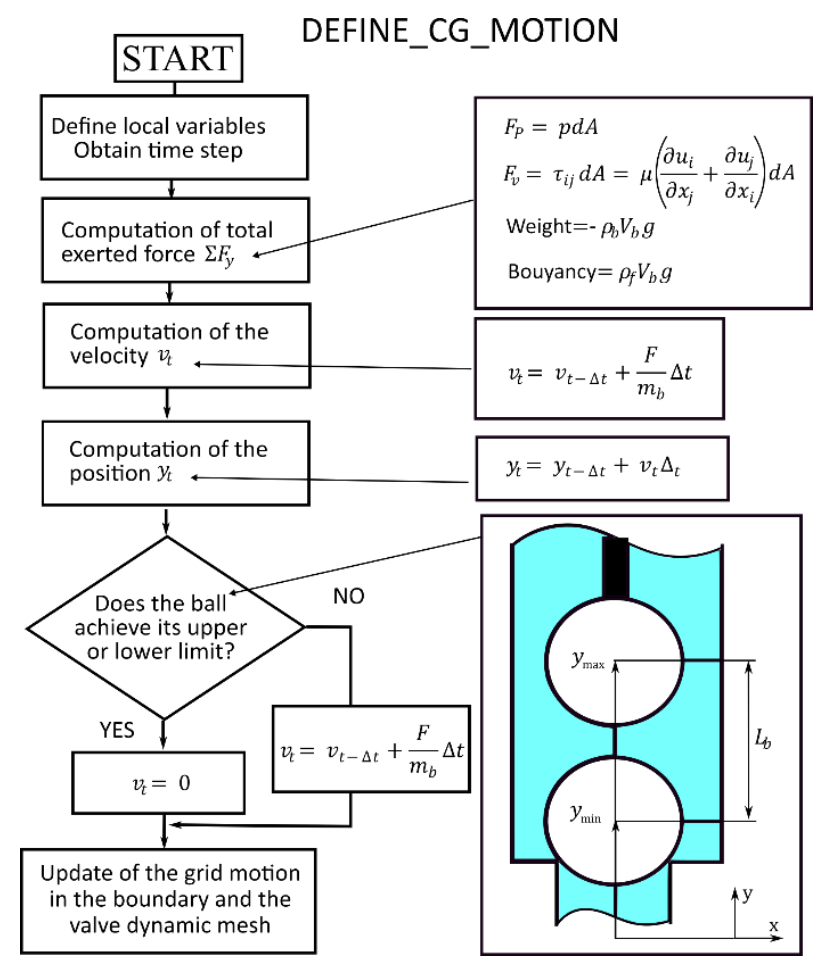

Figure 11. Sequence of the UDFs for the layering routines with the explicit scheme.

\subsection{Explicit VS Implicit schemes.}

The explicit scheme for the grid motion is desirable because allows the updating of the mesh only once at the beginning of every time step using the flow variables from the previous instant. Figure 12, left, shows how the complete explicit routines for layering and remeshing techniques are incorporated in the computational procedure of the ANSYS-FLUENT solver. However, significant restrictions arise for the grid motion in order not to violate the mesh Courant number [30], i.e. balls and diaphragms motions should not exceed the size of the collapsing cells. Typically, this requires the employment of reduced time steps (below $5 \cdot 10^{-5} \mathrm{~s}$ for the grid density of the static model).

Another important restriction is associated to the very small gaps used for the closure of the valves in the dynamic mesh. Since a complete closure is not possible (in order to avoid singularities, the mesh cannot be completely vanished), a minimum clearance has to be maintained for realizability of the model. Hence, it has been fixed to $0.15 \mathrm{~mm}$ (a $0.5 \%$ of the ball diameter) in the present simulations, preserving only 2 cells in the valve seat gap. In addition, due to the highly-refined meshes in that region $\left(y^{+}=4 \div 9\right)$, an Enhanced Wall Treatment (EWT) was also employed for the turbulence modelling [31]. A hybrid mesh with approximately 33000 cells was finally used for the whole domain. 
This is an additional problem for the explicit scheme because of the extremely reduced time steps required when the balls are closing the check valves. Preliminary simulations, under free-discharge conditions, exhibited problems of convergence due to unstable calculations of the forces acting on the balls and non-realistic velocity estimations. Additional attempts reducing the time steps from $10^{-5}$ to $10^{-6}$ and even $10^{-7}$ did not resolve the problems. After a few cycles, the instabilities are amplified and the simulations blow-up due to the mesh corruption produced by an out-of-scale motion of the balls (figure 12, right).

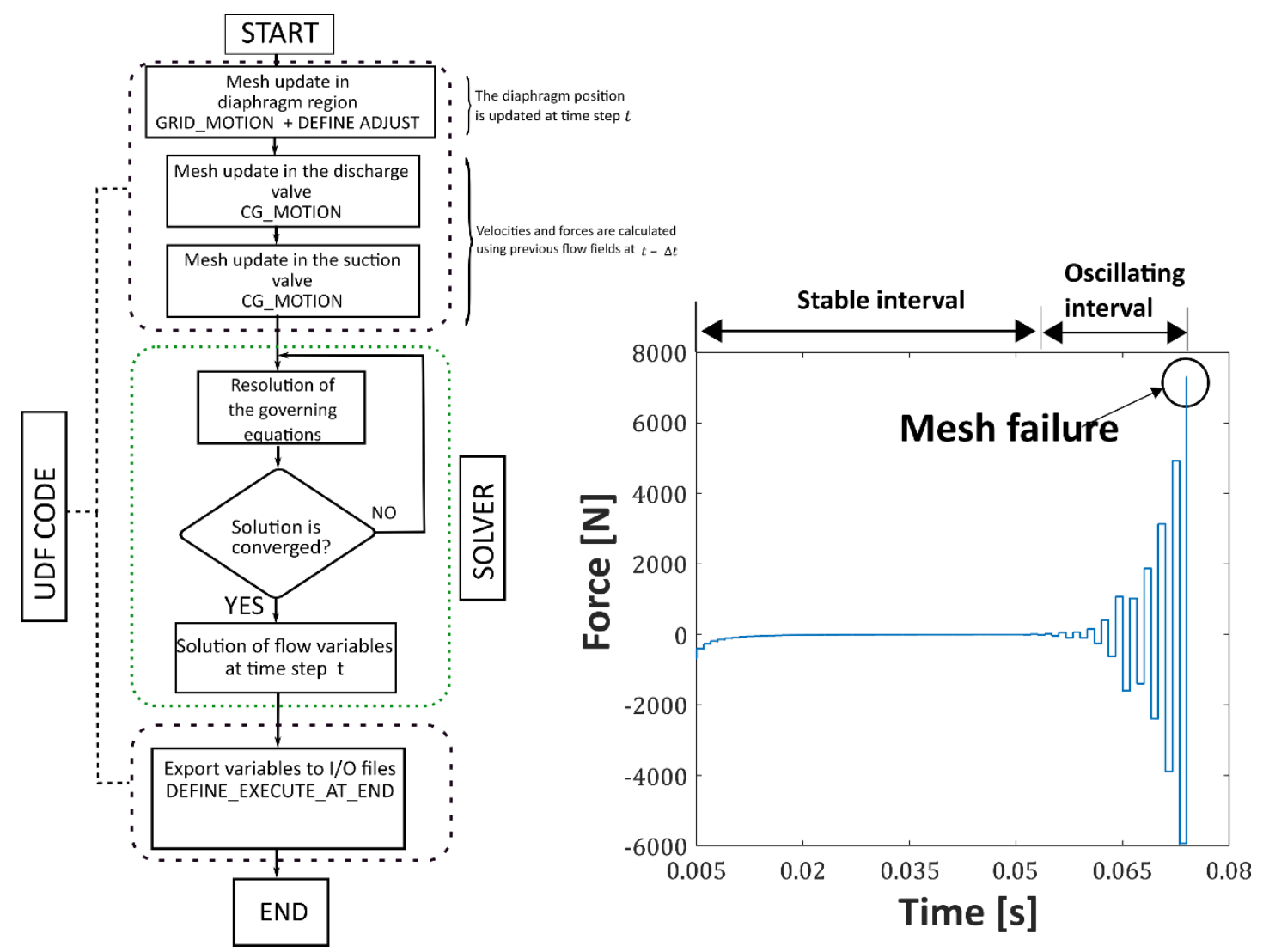

Figure 12. Flowchart for the explicit scheme (left) and diverging instabilities in the computation of the fluid forces exerted on the balls (right).

Most of the simulation parameters were also modified without significant progress: high-order discretization schemes, other turbulence models ( $S-A, k-\omega)$, coupled solver and even other remeshing strategies in the check valves. Hence it is concluded that there is a high coupling between the solid-body motion of the balls and the fluid-flow structures (FSI) that cannot be solved with a conventional explicit scheme for the grid motion.

To confirm this hypothesis, a simplified case with a diaphragm and a single ball without valve-seat restrictions was modelled. The ball was encapsulated with a structured mesh and the UDFs were also simplified considering remeshing only with the explicit scheme 
(Figure 13, left). It was observed a clear trend for numerical instability and a high dependency on the time step size. Figure 13, right, shows the evolution of the force exerted over the ball for several cycles of the diaphragm motion, as the time step is progressively reduced. Only a narrow range of time steps derives in a controlled evaluation of the force. If the time step is high, large oscillations arise in the computations of the force; but if the time step is too reduced, new instabilities are also produced. Consequently, the realizability of the model is seriously compromised and difficult to be determined in aprioristic basis.
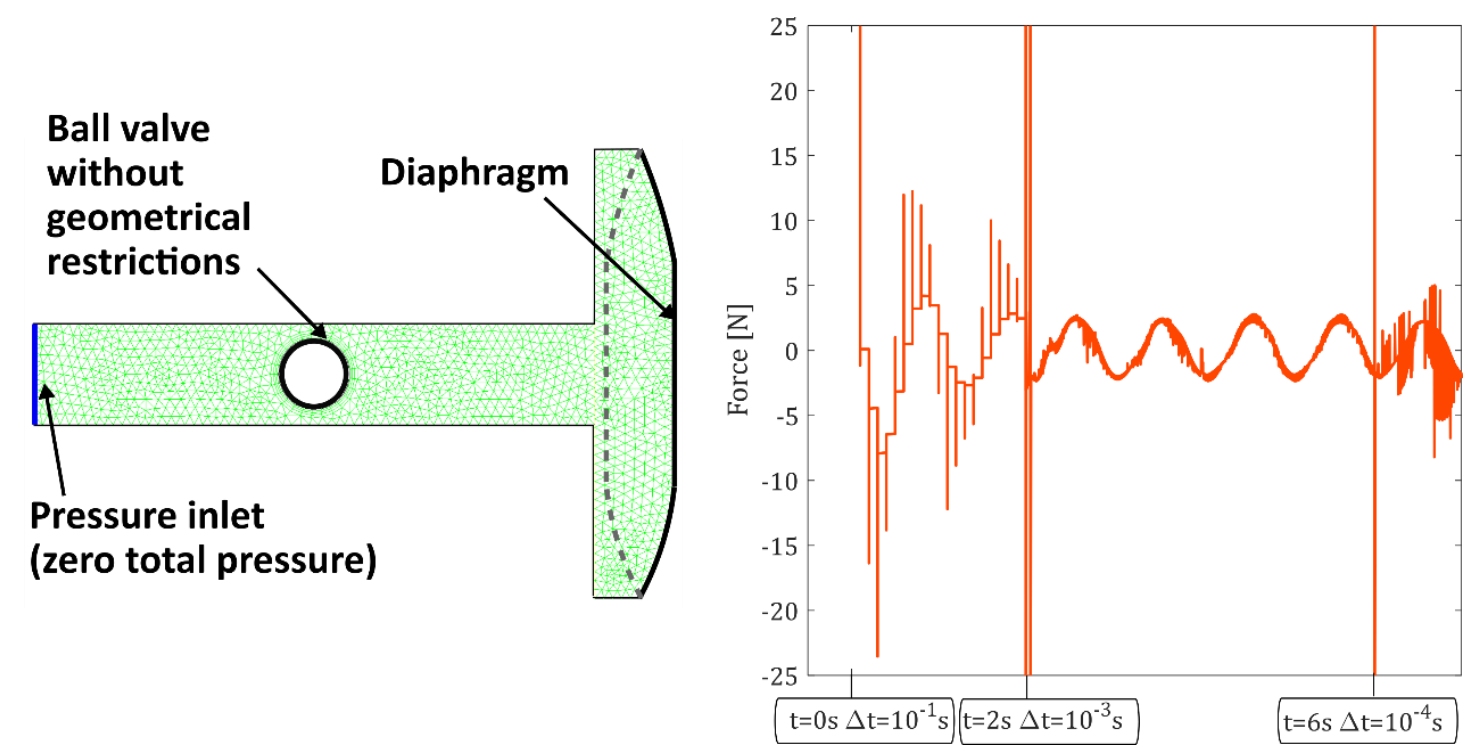

Figure 13. Simplified model for the evaluation of the explicit scheme (left) and temporal evolution of the force in the ball as a function of the time step size (right).

Effectively, the employment of explicit schemes in fluid-solid interactions is not recommended when the density ratio of the fluid with respect to the solid is around or above unity (here, the balls are made of PTFE with a typical density of $2200 \mathrm{~kg} / \mathrm{m}^{3}$ ). Small pressure fluctuations may lead to significant oscillations in the body motion and eventually set off an unstable feedback that breaks up the simulation [32], as previously evidenced. Therefore, the numerical methodology was reoriented towards an implicit scheme, despite of the large CPU times required. The significant increment of the computational costs is based on the grid updating that must be completed now at every iteration in the time step. Approximately, 400 hours (2-3 weeks) of CPU time were necessary to resolve one single cycle of the diaphragm in the two-dimensional domain of $33 \mathrm{~K}$ cells using a 4-nodes Intel Core i7-5820K at 3.3 GHz and 64Gb RAM.

Previous UDFs are re-used, but now updating both local and global variables in every iteration. In order to improve the coupling between the velocity and the forces acting on the balls, a second-order backward approach is also employed to calculate the velocity of the balls: 


$$
v_{t}=\left(4 v_{t-\Delta t}-v_{t-2 \Delta t}+2\left(\frac{F}{m_{b}}\right) \Delta t\right) / 3
$$

The convergence of the implicit scheme for the mesh is also enhanced introducing under-relaxing factors during the iterative process in a given time step. The following equation is implemented [25] to control the relative changes in the grid velocity between consecutive iterations:

$$
v_{t}^{(n)}=v_{t}^{*(n)} \omega_{r}+\left(1-\omega_{r}\right) v_{t}^{(n-1)}
$$

where $n$ indicates the current iteration, $v_{t}^{(n-1)}$ stands for the velocity computed in the previous iteration, $v_{t}^{*(n)}$ is the non-relaxed velocity for the current iteration and $\omega_{r}$ is the under-relaxing factor (that must be fixed between 0 and 1 ). To speed up the whole calculation, the under-relaxing factor is re-calculated in every iteration according to the following mathematical expression:

$$
\omega_{r}=1-r_{1} e^{-\left(\frac{n^{2}}{r_{2}}\right)}
$$

$r_{1}$ defines the under-relaxing factor in the first iteration, while $r_{2}$ controls the asymptotic evolution of the relaxing factor towards unity (i.e., when $\omega_{r}$ is no longer relaxing). In the present simulations, the values $r_{1}=0.8$ and $r_{2}=500$ were found to provide a reasonable ratio between economy and accuracy.

In addition, the mesh updating was finally not performed at every iteration. Only during the first numbers of iterations, the update was maintained without skipping. After the initial five iterations, the update was performed every two iterations and finally after every five iterations. Figure 14, right, shows the asymptotic evolution of the underrelaxing factor (black solid line), and the iterating intervals for the mesh to be updated. Note how the oscillations in the calculation of the force (red line) are damped during the initial iterations.

All these features have allowed to economize the computational costs and also to increase the time step sizes without divergence issues. The instabilities leading to nonrealistic motions and mesh divergence during the initial iterations of the critical time steps (those in the proximity of the valve seat) are now under control. Figure 14, left, shows the definitive flowchart of the dynamic calculations with UDFs for the implicit scheme. 


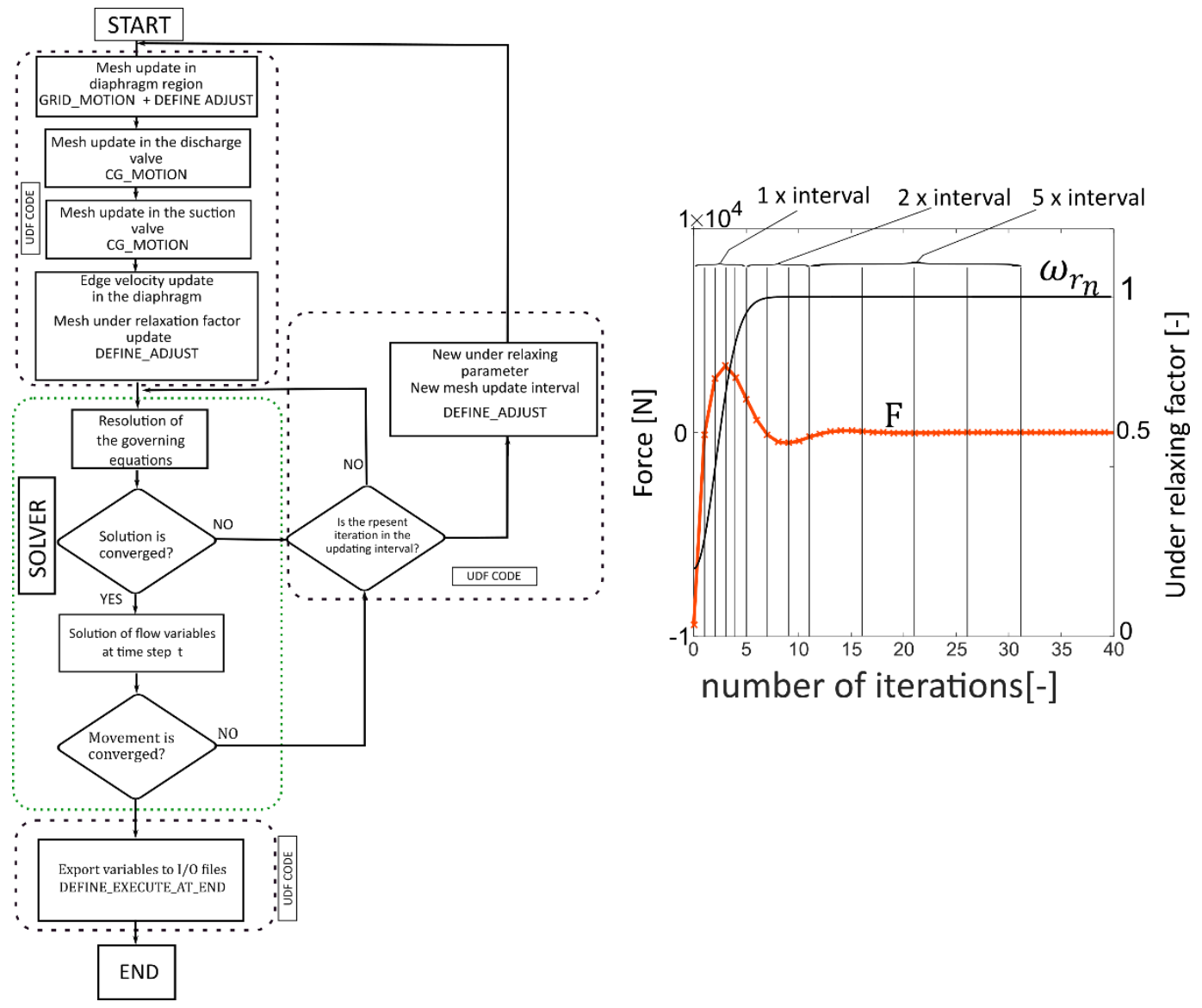

Figure 14. Evolution of the under-relaxing factors and grid updating intervals in a time step (right) and final flowchart for the implicit scheme (left).

\subsection{Final unsteady resolution with FSI.}

The final numerical model with implicit scheme for the mesh update in the moving zones was executed for all the operating points characterized experimentally. To reproduce the different cases, the outlet boundary condition (a pressure drop proportional to the kinetic energy) had to be fixed changing the value of the loss coefficient. Note that this procedure mimics the partial closure of the throttle valve in the experiments. Precisely, the loss coefficient is estimated from the experiments, computing the ratio between the RMS value of the static pressure measured with the electronic manometer (see figure 15 , left) and the mean bulk velocity at the pump discharge:

$$
K_{v}=\frac{P_{R M S}}{\rho \bar{v}^{2}}=\frac{\pi^{2} D_{m}^{4} P_{R M S}}{16 \rho Q^{2}}
$$

The different loss coefficients used for the numerical simulations are presented in Table 5 below (fourth column). The time step used in every case and the driving frequency imposed for the diaphragm (measured experimentally) is also given in the table. Note 
that, from a physical point of view, it is necessary to preserve a reasonable Courant number (around unity) in order to obtain a resolution with physical sense when performing the unsteady computations. Considering that the smallest cells in the valve seats are in the order of a fraction of a millimeter (10-4 $\mathrm{m}$ ), with expected velocities in the range of $2.5 \mathrm{~m} / \mathrm{s}$, time steps were fixed in the order of 5.10-5 to $10-5$ as a convenient selection for accuracy and stability.

Table 5. Numerical database. Outlet BC and time step sizes.

\begin{tabular}{cccccc}
\hline $\begin{array}{c}\text { Test } \\
\text { No. }\end{array}$ & $\begin{array}{c}\text { Supplied } \\
\text { pressure } \\
\text { (bar) }\end{array}$ & $\begin{array}{c}\text { Discharge } \\
\text { pressure, } \\
\mathbf{P}_{\text {RMS }}(\text { bar) }\end{array}$ & $\begin{array}{c}\text { Loss } \\
\text { coefficient, } \\
\mathbf{K}_{\mathrm{v}}(-)\end{array}$ & $\begin{array}{c}\text { Driving } \\
\text { frequency }(\mathbf{H z})\end{array}$ & $\begin{array}{c}\text { Time step, } \mathbf{\Delta t} \\
(\mathbf{s})\end{array}$ \\
\hline$\# 1$ & 2 & 0 & 0 & 1.85 & $5 \cdot 10^{-5}$ \\
$\# 2$ & 2 & 1.16 & 75.1 & 1.0 & $5 \cdot 10^{-5}$ \\
$\# 3$ & 4 & 0 & 0 & 2.45 & $5 \cdot 10^{-5}$ \\
$\# 4$ & 4 & 1.99 & 62.1 & 1.4 & $5 \cdot 10^{-5}$ \\
$\# 5$ & 4 & 3.65 & 1411 & 0.45 & $5 \cdot 10^{-5}$ \\
$\# 6$ & 6 & 0 & 0 & 2.7 & $2.5 \cdot 10^{-5}$ \\
$\# 7$ & 6 & 1.97 & 32.5 & 1.8 & $2.5 \cdot 10^{-5}$ \\
$\# 8$ & 6 & 3.63 & 139.9 & 1.25 & $5 \cdot 10^{-5}$ \\
$\# 9$ & 6 & 4.14 & 500.8 & 0.75 & $5 \cdot 10^{-5}$ \\
\hline
\end{tabular}

In addition, it was necessary to run the simulations during two initial cycles to eliminate the transient state in the pump. Of course, this increased notably the required CPU time, but it is unavoidable to obtain a representative solution for the model. A fully-periodic response was achieved from the third cycle on, so monitoring of the relevant variables and significant intermediate positions was then activated.

\section{NUMERICAL RESULTS}

\subsection{Comparison of performance curves}

After the application of the scaling factors defined in eq. (6), the delivered flow rate in the two-dimensional model, as a function of the discharge pressure, is compared with the experimental curves in figure 15, right. All the flowrate results have been duplicated taken into account the existence of two symmetric diaphragms in a parallel arrangement. Even with the 2D flow assumption, it is noticeable the overall good agreement, especially at high discharged pressures. At atmospheric outlet conditions, the numerical model overpredicts the delivered flowrate because of the relevant mechanical losses (friction) at low pressure regimes that the simulations are not modelling. For all the air-supplied pressures, the discrepancy between the experimental and numerical values is enlarged as the output pressure decreases. The higher discrepancy is around a $9 \%$ in the case of the 4 bar curve at free-delivery conditions.

The plot in figure 15, right, also highlights two nominal points (at moderate discharge pressures) representing the situations for high (6 bar) and low (2 bar) air-supplied pressures. This is equivalent to high $(1.8 \mathrm{~Hz})$ or low $(1.0 \mathrm{~Hz})$ driving velocities. The 
evolution of the flow rate and the motion of the check valves for these operating points will be discussed in detail in the following subsection.
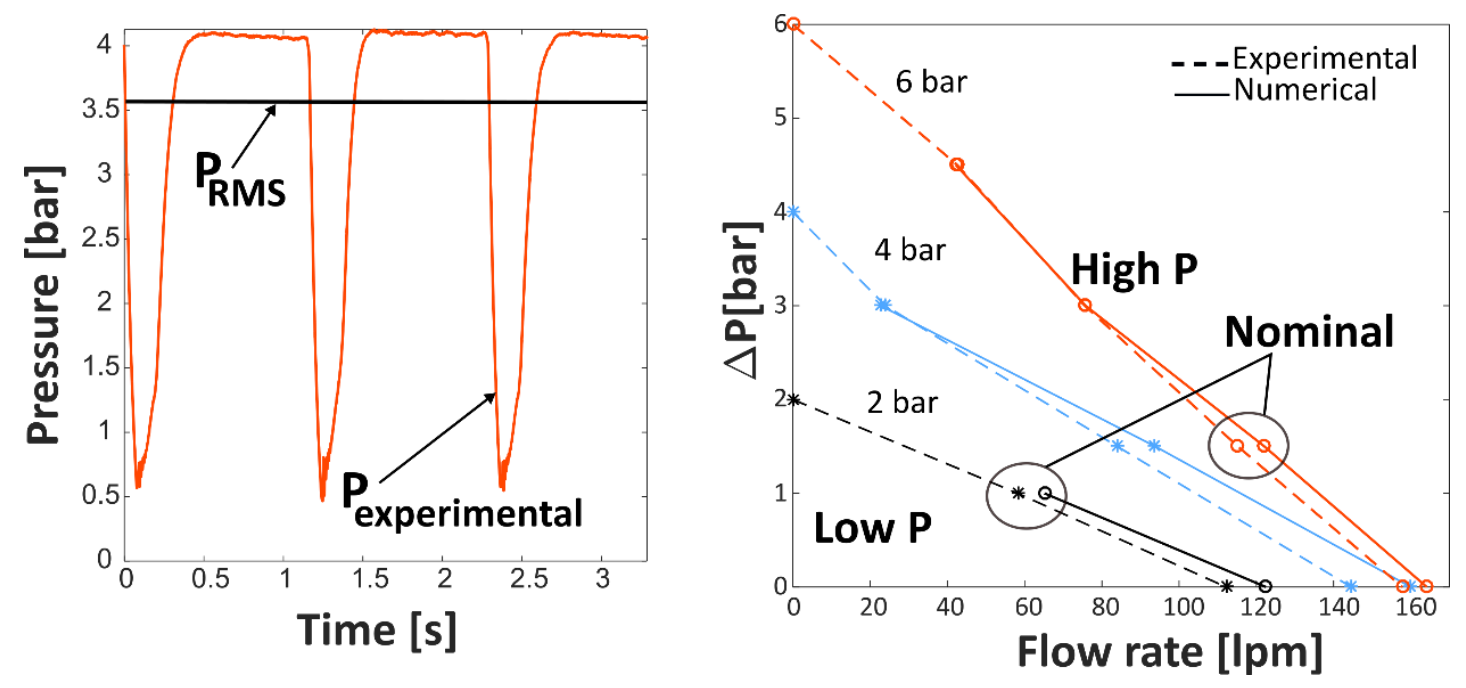

Figure 15. Left: Static pressure at the pump discharge (red line) and its computed RMS value (black line) for Test \#5. Right: Comparison of CFD and experimental results.

\subsection{Nominal operation.}

Following, the evolution of the pressure in the diaphragm chamber and at the pump outlet, as well as the flowrate and the position of the check valves, are monitored during a converged diaphragm cycle (denoted as period, T). Figure 16, left, shows the results for the high air-supplied pressure.

The pressure in the chamber rises abruptly with two significant peaks at the beginning of the diaphragm displacement. The maximum pressure coincides with the middle position of the forward stroke of the diaphragm (black line at $t=T / 4$ ). At that moment, the exhausting valve is completely opened but with the ball starting to drop. Between $\mathrm{T} / 4$ and $\mathrm{T} / 2$, the delivered flow rate experiences a sudden bump, associated to a partial re-opening of the exhaust valve. In the second half of the cycle, the diaphragm is suctioning fluid and the incoming flow exhibits a sinusoidal pattern, in total agreement with the theoretical response (dashed lines). Note that the model is capable to reproduce the inertial delays in the openings and closings of the valves, which are identified as local decays of the flowrates at the beginning of the back-and-forth movements.

Figure 16, right, shows a similar representation but for the case with low-pressure. All the evolutions of the delivered flow rate and the pressure in the pump behave more theoretically. However, due to the lower pressure, there are much more oscillations of the exhausting ball, which represents a continuous tapping (high-frequency noise) and the origin of instabilities in the closure of the check valve. This feature is well-known by the pump manufacturer. 

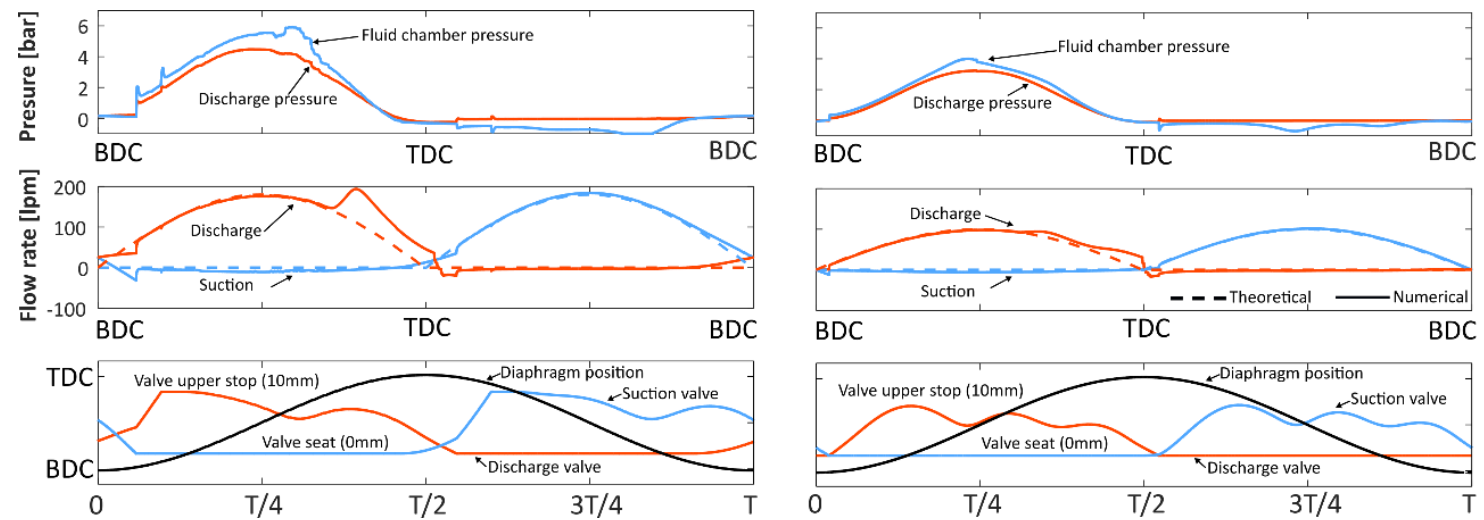

Figure 16. Temporal evolutions of the pressure, flow rates and check valves during the diaphragm cycle for high-pressure (left) and low-pressure (right) nominal conditions.

To provide more insight, Figure 17 represents the associated description of the flow patterns at four relevant intermediate positions of the diaphragm cycle for the highpressure situation. Only at $\mathrm{T} / 4$ the exhausting valve is partially opened; in the rest of the snapshots, it is practically closed. It is quite significant the appearance of several recirculating cells of fluid all through the internal passages, especially in the final contour at the BDC of the diaphragm $(\mathrm{t}=\mathrm{T})$. This can be indicating the need for a full 3D geometry for a more realistic description of the internal flow. This evidence is also associated with the fact that the flow in the gap of the valves is developed with a two high-velocity jets structure at both sides of the ball. Obviously, this is a clear restriction of the 2D geometry, that probably may be different in a real 3D model where the flow can be circumferentially redistributed around the ball. Note also the flow separation in the outlet manifold at $\mathrm{t}=\mathrm{T} / 4$ and the accurate guidance of the suctioning flow when it is introduced in the diaphragm chamber $(t=3 T / 4)$.

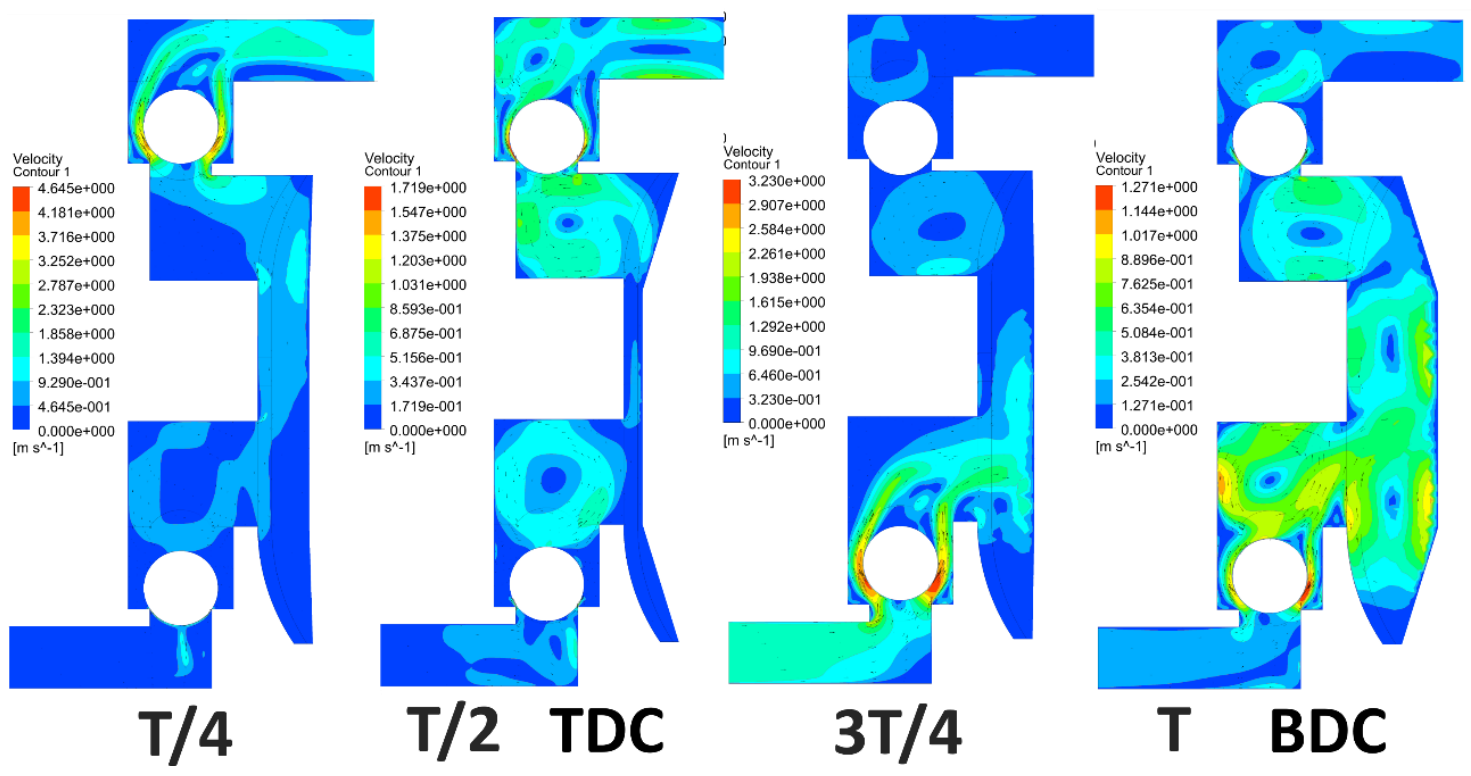

Figure 17. Description of the flow patterns for the high-pressure conditions (6 bar). 


\subsection{Free-delivery conditions.}

To conclude, free-outlet conditions are also analyzed for high (6 bar) and low (2 bar) airsupplied pressures. Because of the atmospheric conditions at the pump discharge, the driving frequencies of the diaphragm are increased to 2.7 and $1.85 \mathrm{~Hz}$ respectively.

Figure 18, left, shows the evolutions of the main parameters for the high pressure case. Note that significant pressures (up to 2 bar) are attained in the diaphragm chamber during the forward stroke. The most relevant characteristic is the long delay for the closure of the exhausting valve, between $t=0$ and $T / 8$. Consequently, there is a very important reduction of the delivered flow rate when the single diaphragm is pumping. The ball experiences a similar drop after reaching its upper stopper (between $T / 4$ and $T / 2$ ). This is also manifested with a characteristic flowrate bumping when the diaphragm is decelerating towards its TDC that reveals significant instabilities. Finally, in the second half of the cycle, it is also noticeable the same delay problem in the other valve, with a notable internal leakage for the suctioning flow rate between $\mathrm{T} / 2$ and $5 T / 8$.

For the lower pressure case, Figure 18 (right), all the variables exhibit a similar behavior. However, since the pressure in the diaphragm chamber is lower, the flowrate bumping at the end of the forward stroke is also less pronounced. As a consequence, due to a smoother transition for the closure of the exhausting valve, the leakage in the suction valve is clearly attenuated.
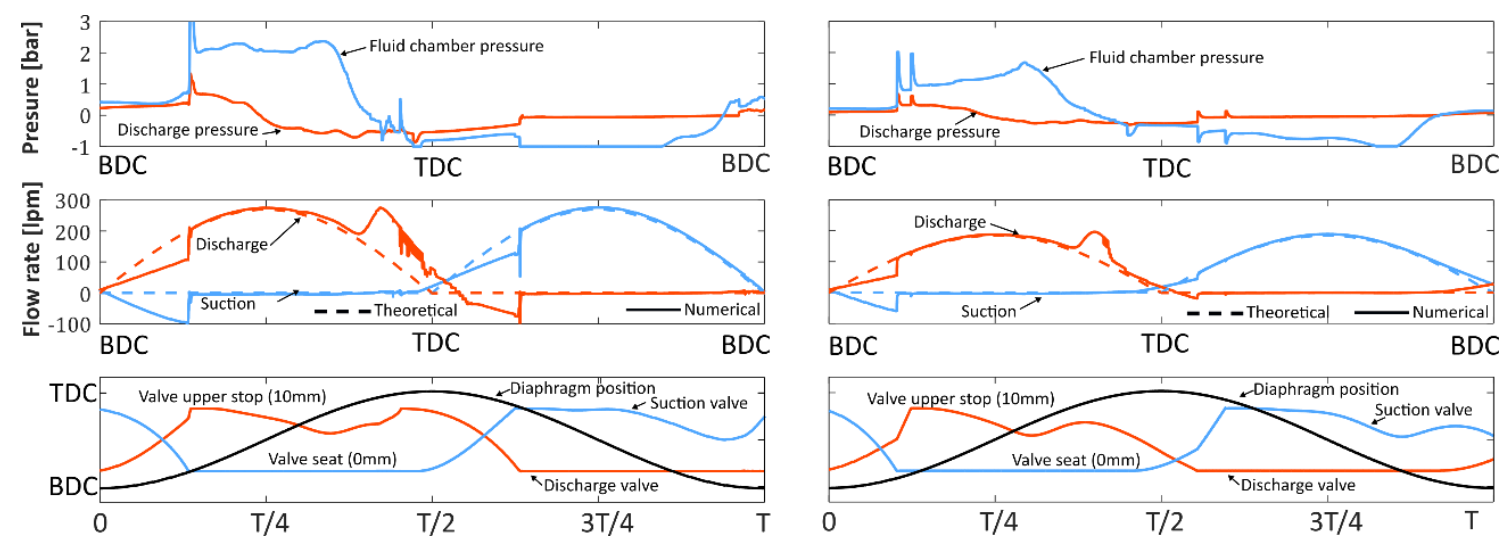

Figure 18. Temporal evolutions of the pressure, flow rates and check valves during the diaphragm cycle for high-pressure (left) and low-pressure (right) free-delivery conditions.

A closer look to the behavior of the valves is presented in Figure 19 with the representation of the forces and velocities obtained in the balls during the back-andforth motions of the diaphragm. The black solid line represents the valve displacement, the thin solid line is the ball velocity and the dashed line is the force acting on the ball. Plots on top correspond to the exhausting check valve, whereas plots on the bottom show the behavior of the valve in the suction region. As before, left column shows the results for the high pressure and the right column for the low pressure. 
The most significant feature is the strong coupling between the movements of the balls. Note, for instance, how during the closure of the exhausting valve in the low pressure case, there is an evident slope change during its displacement, accelerated in the final part of the closure. This effect is clearly produced by the total closure of the suction ball when it reaches the valve seat.

Another example is clearly observed in the high pressure case. After a partial re-opening of the exhausting valve between $T / 4$ and $T / 2$, the valve is closed again, exhibiting some oscillations in its vertical velocity, but also significant force fluctuations arise in the suction valve (which is completely closed) in return. In addition, note how negative forces (to close the valves towards their seats) are easily maintained, while positive forces are not stable (due to gravity) so the balls cannot be maintained completely opened for the full stroke.
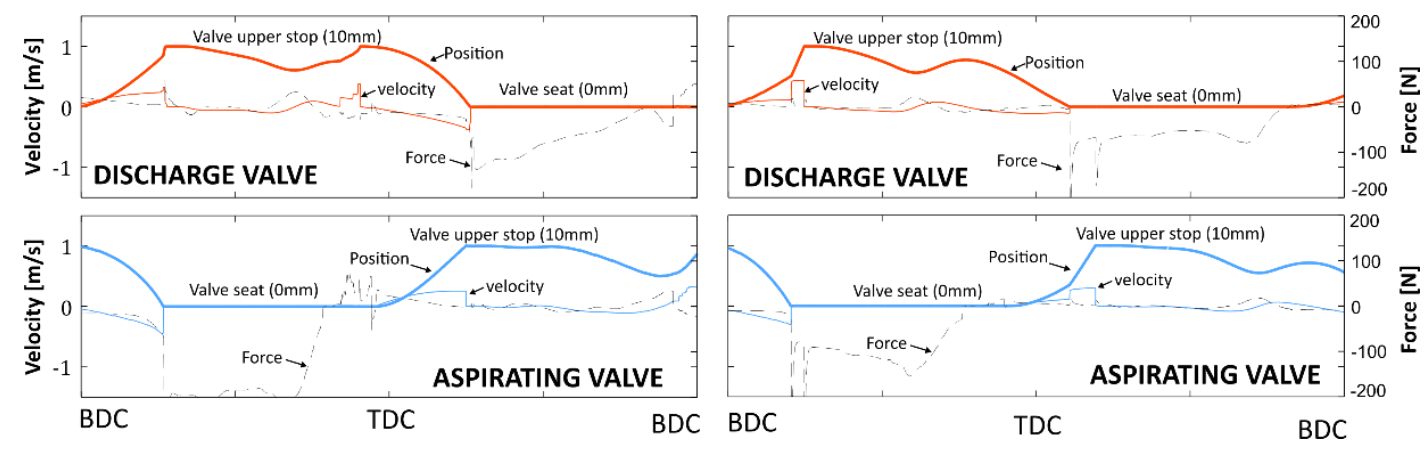

Figure 19. Temporal evolutions of the velocity and forces on the check valves during the diaphragm cycle for high-pressure (left) and low-pressure (right) free-delivery conditions.

\section{CONCLUSIONS}

An unsteady numerical methodology for the CFD simulation of Air-Operated Double Diaphragm (AODD) Pumps has been developed using dynamic meshes with layering and remeshing techniques. In particular, a set of User Defined Functions (UDFs) were developed to model accurately the dynamic movement of the pump diaphragm, implemented with a prescribed sinusoidal motion, and the opening and closure of the check valves, fully-resolving the Fluid Structure Interaction (FSI) over the balls.

In addition, an implicit scheme for the grid motion was found to be necessary for the stability and realizability of the model adopted. Explicit schemes, less time-consuming, exhibited divergence problems for the check balls approaching the valve seats even with extremely reduced time steps. A simplified model, without geometrical restrictions for the ball stroke, also confirmed this evidence. Moreover, to speed up the implicit iterative process, an adaptive updating of the mesh motion, reinforced at the initial iterations of every time step, was also introduced. 
The numerical database was validated with a set of experimental tests performed in the Prototypes Laboratory of the R\&D Department at SAMOA Industrial S.A. Different airsupplied pressures and outlet discharge pressures for the pump were considered in order to obtain the delivered flow rate and the diaphragm reciprocating frequency. Some of this data was also employed as BCs for the numerical model and scaling factors for the pressure and the velocities in the $2 \mathrm{D}$ model were defined to allow the comparison between the CFD results and the real performance curves of the pump.

A detailed analysis of the working parameters of the pump (displacement of the check valves, instantaneous flow rate and discharge pressure) has revealed significant internal leakages, especially for the exhausting valve at low pressure regimes. In the case of high pressure conditions, the relevant feature is the arising of a sudden ripple in the delivered flow rate when the diaphragm is decelerating in the forward stroke. Whatever the case, the exhausting valve and the corresponding flow rate is more susceptible for instabilities than the incoming flow through the suction region. Furthermore, at lower pressure, the exhausting ball is continuously fluctuating towards its end position, revealing a wellknown tapping phenomenon that causes vibration and tonal noise. When working at atmospheric conditions, the behavior found in the different elements is similar, but with more pronounced leakages in the exhausting valve.

A closer look to the balls dynamics has also revealed the strong coupling between inlet and outlet check valves. This is clearly evidenced with the delay of the exhausting valve opening which is accelerated after the complete closure of the suction valve. Another example are the instabilities arising in the forces exerted on the balls as a consequence of the partial re-openings in the other valve.

Finally, despite of the remarkable accuracy attained with the simulations (maximum deviations of a $9 \%$ in the estimation of the flow rate), the recirculating cells and the flow characteristics around the check valves, shown in the representation of the flow patterns inside the pump, suggest the convenience for a complete 3D modelling of the pump. Future work will be focused on the development of a full-unsteady 3D model of an AODD pump using the presented methodology with dynamic meshes.

\section{ACKNOWLEDGEMENTS}

The authors acknowledge the technical support and collaboration given by SAMOA Industrial S.A. during the execution of this Research and its kind permission for publication. Also, the financial support from the University Institute of Industrial Technology of Asturias (IUTA) under R+D+i Project "Application of CFD Modelling for the Design of Air-Operated Diaphragm Pumps" is gratefully recognized. 


\section{NOMENCLATURE}

$\Delta p_{2 D} \quad$ Pressure drop (2D model value)

$\Delta p_{3 D} \quad$ Pressure drop (3D real experimental value)

$\Delta t \quad$ Time step size

$\omega_{r} \quad$ Under-relaxation factor

$\bar{v} \quad$ Mean bulk velocity at the pump discharge

$\rho \quad$ Fluid density

$A_{d} \quad$ Diaphragm effective area, node displacement amplitude

$A_{v} \quad$ Check valve effective area

$A O D D$ Air-Operated Double Diaphragm (pump)

$B D C$ Bottom Dead Center

CFD Computational Fluid Dynamics

$D_{d} \quad$ Diaphragm effective diameter

$D_{e} \quad$ Diaphragm external diameter

$D_{i} \quad$ Diaphragm internal diameter

$D_{m} \quad$ Internal manifolds diameter

$D_{v} \quad$ Ball diameter of the check valves

$D P \quad$ Directflo ${ }^{\circledR}$ Pump

EPDM Ethylene Propylene Diene Monomer

$F \quad$ Force exerted by the Fluid on the ball valves

$f \quad$ Reciprocating frequency

FSI Fluid-Structure Interaction

$K_{v} \quad$ Pressure loss coefficient

$L_{d} \quad$ Diaphragm stroke length

$L_{v} \quad$ Ball maximum displacement

$m_{b} \quad$ Mass of the valve ball

$n \quad$ Driving frequency, current iteration

$p_{R M S} \quad$ Root-mean-square value of static pressure

$p_{\text {air }} \quad$ Air operating pressure

PTFE Poly Tetra Fluoro Ethylene

$Q \quad$ Pump flow rate

$r_{1} \quad$ First parameter for the recalculation of the under-relaxation factor

$r_{2} \quad$ Second parameter for the recalculation of the under-relaxation factor

$t \quad$ Simulation time

TDC Top Dead Center

$V_{b} \quad$ Volume of the valve ball

$V_{d} \quad$ Delivery (volumetric capacity) per stroke

$v_{t}^{* n} \quad$ Non-relaxed velocity computed in the iteration $\mathrm{n}$

$v_{t}^{n} \quad$ Velocity computed in the iteration $\mathrm{n}$

$v_{2 D} \quad$ Bulk velocity (2D model value)

$V_{3 D} \quad$ Bulk velocity (3D real experimental value)

$x_{P} \quad$ Position of a mesh node co-located with the pump diaphragm

$y_{t} \quad$ Position of the ball valve at time $\mathrm{t}$

\section{REFERENCES}

[1] Bahrton, S., "Double Acting Pump," US Patent 6299415 B1, 2001.

[2] Wilden, J.K., “Air Driven Diaphragm Pump,” US Patent 4247264 A, 1981. 
[3] Gardner, R.K.; Kozumplik, N.J., “Double Diaphragm Pumps,” EP Patent 0304210 B1, 1992.

[4] Bahrton, S., "Reversing Valve for a Diaphragm Pump," US Patent 6419463 B1, 2002.

[5] González-Moratiel, A., "Double-Membrane Central-Flow Pump," EP Patent 2573397 A1, 2013.

[6] ANSI/HI. 10.1-10.5, “Air Operated Pumps for Nomenclature, Definitions, Application and Operation," Hydraulic Institute, 2010.

[7] ANSI/HI. 10.6, “Air Operated Pump Tests," Hydraulic Institute, 2004.

[8] Pei, J.; He, C.; Lu, M.; Huang, X.; Shen, K.; Bi, K., "The Valve Motion Characteristics of a Reciprocating Pump," Mechanical Systems and Signal Processing, vol. 66-67, pp. 657-664, 2016.

[9] Opitz K.; Schlücker, E., "Detection of Cavitation Phenomena in Reciprocating Pumps using a High-Speed Camera," Chemical Engineering \& Technology, vol. 33 (10), pp. 1610-1614, 2010.

[10] Edge, K.A.; Brett, P.N.; Leahy, J.C., "Digital-Computer Simulation as an Aid in Improving the Performance of Positive Displacement Pumps with Self-Acting Valves," Proceedings of the IMechE, Part B, Journal of Engineering Manufacture, vol. 198 (14), pp. 267-274, 1984.

[11] Johnston, D.N., "Numerical Modelling of Reciprocating Pumps with Self-Acting Valves," Proceedings of the IMechE, Part I, Journal of Systems and Control Engineering, vol. 205 (2), pp. 87-96, 1991.

[12] Shu, J.-J.; Burrows, C.R.; Edge, K.A., "Pressure Pulsations in Reciprocating Pump Piping Systems. Part 1: Modelling," Proceedings of the IMechE, Part I, Journal of Systems and Control Engineering, vol. 211 (3), pp. 229-237, 1997.

[13] Lee, J.K.; Jung, J.K.; Chai, J.-B.; Lee, J.W., "Mathematical Modeling of Reciprocating Pump," Journal of Mechanical Science and Technology, vol. 29 (8), pp. 3141-3151, 2015.

[14] Ragoth, R.S.; Nataraj, M., "Study on Performance of Plunger Pump at Various Crank Angle Using CFD," Engineering Science and Technology: An International Journal, vol. 2 (4), pp. 549-553, 2012.

[15] Iannetti, A.; Stickland, M.T.; Dempster, W.M., “A Computational Fluid Dynamics Model to Evaluate the Inlet Stroke Performance of a Positive Displacement Reciprocating Plunger Pump," Proceedings of the IMechE, Part A, Journal of Power and Energy, vol. 228 (5), pp. 574-584, 2014.

[16] Iannetti, A.; Stickland, M.T.; Dempster, W.M., "A CFD Study on the Mechanisms Which Cause Cavitation in Positive Displacement Reciprocating Pumps," Journal of Hydraulic Engineering, vol. 1 (1), pp. 47-59, 2015. 
[17] Iannetti, A.; Stickland, M.T.; Dempster, W.M., "A CFD and Experimental Study on Cavitation in Positive Displacement Pumps: Benefits and Drawbacks of the 'Full' Cavitation Model," Engineering Applications of Computational Fluid Mechanics, vol. 10 (1), pp. 57-71, 2016.

[18] Menéndez-Blanco, A.; Fernández Oro, J.M., "Unsteady Numerical Simulation of an Air-Operated Piston Pump for Lubricating Greases using Dynamic Meshes," Computers \& Fluids, vol. 57, pp. 138-150, 2012.

[19] Bergada, J.M.; Kumar, S.; Davies, D.Ll.; Watton, J., "A Complete Analysis of Axial Piston Pump Leakage and Output Flow Ripples," Applied Mathematical Modelling, vol. 36 (4), pp. 1731-1751, 2012.

[20] Kumar, S.; Bergada, J.M.; Watton, J., “Axial Piston Pump Grooved Slipper Analysis by CFD simulation of Three-Dimensional NVS Equation in Cylindrical Coordinates," Computers \& Fluids, vol. 38, pp. 648-663, 2009.

[21] Srikanth, C.; Bhasker, C., "Flow Analysis in Valve with Moving Grids through CFD Techniques," Advances in Engineering Software, vol. 40 (3), pp. 193-201, 2009.

[22] Xu, H.; Guang, Z.M.; Qi, Y.Y., "Hydrodynamic Characterization and Optimization of Contra-Push Check Valve by Numerical Simulation," Annals of Nuclear Energy, vol. 38 (6), pp. 1427-1437, 2011.

[23] Beune, A.; Kuerten, J.G.M.; van Heumen, M.P.C., "CFD Analysis with FluidStructure Interaction of Opening High-Pressure Safety Valves," Computers \& Fluids, vol. 64, pp. 108-116, 2012.

[24] Valdés, J.R.; Rodríguez, J.M.; Monge, R.; Peña, J.C.; Pütz, T., “Numerical Simulation and Experimental Validation of the Cavitating Flow through a Ball Check Valve," Energy Conversion and Management, vol. 78, pp. 776-786, 2014.

[25] ANSYS-FLUENT User's Guide. Release 14.0. ANSYS, Inc., 2011.

[26] Patankar, S.V., "Computational Modelling of Flow and Heat Transfer in Industrial Applications," International Journal of Heat and Fluid Flow, vol. 23, pp. 222-231, 2002.

[27] ANSYS-FLUENT Meshing User's Guide. Release 15.0. ANSYS, Inc., 2013.

[28] Riemslagh, K.; Vierendeels, J., Dick, E., "Simulation of Incompressible Flow in Moving Geometries," Von Karman Institute Lecture Series 98-03, VKI, 1998.

[29] Menéndez Blanco, A., "Numerical Modelling of Volumetric Diaphragm Pumps", Ph.D. Thesis (in Spanish), University of Oviedo, Spain, 2017.

[30] Hirsch, C., "Numerical Computation of Internal and External Flows: The Fundamentals of Computational Fluid Dynamics," Ed. Elsevier-ButterworthHeinemann, 2007.

[31] Chen, H.C.; Patel, V.C., "Near-Wall Treatment Turbulence Models for Complex Flows Including Separation," AIAA Journal, vol. 26 (6), pp. 641-648, 1998. 
[32] Wei, G., "An Implicit Method to Solve Problems of Rigid Body Motion Coupled with Fluid Flow," Flow Science Inc., Technical note, FSI-05-TN76, 2006.

This document is a post-print version of the scientific paper published by Elsevier. It has been released by the authors to fulfill all the publisher requirements established for Article Sharing: https://www.elsevier.com/about/policies/sharing

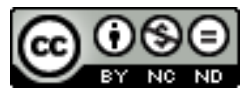

(C) 2019. This manuscript version is made available under the Creative Commons Attribution-NonCommercial-NoDerivatives 4.0 International License

(CC-BY-NC-ND 4.0 license)

http://creativecommons.org/licenses/by-nc-nd/4.0/ 